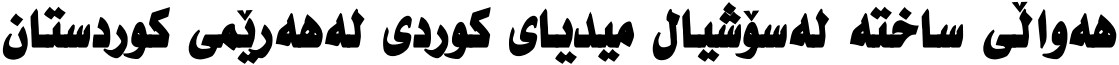

نلهوزاد سليق محهمهد

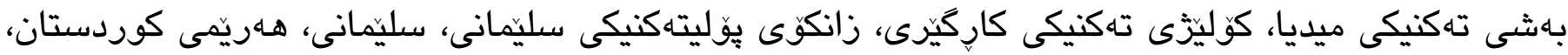
عينراق. nيمهيل: nئيزي

\section{كامل عمر سليمان}

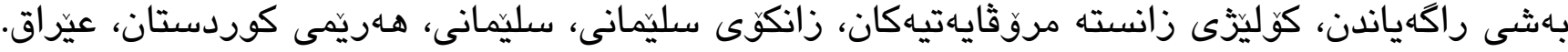

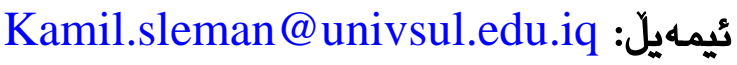

يوخته

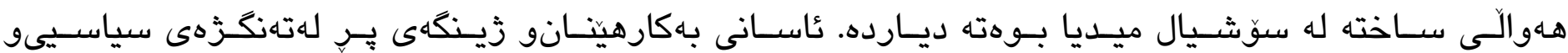

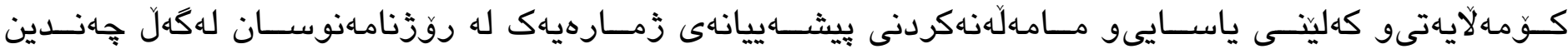

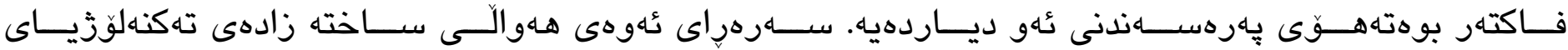

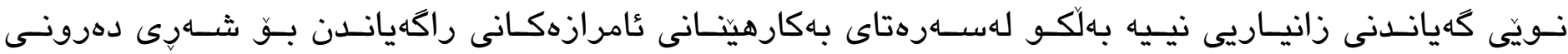

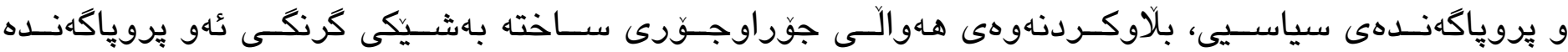

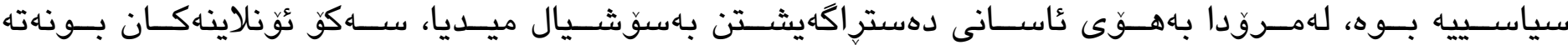

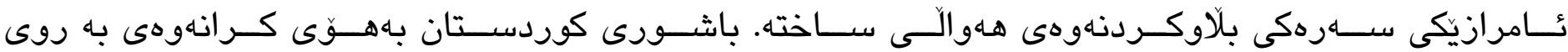

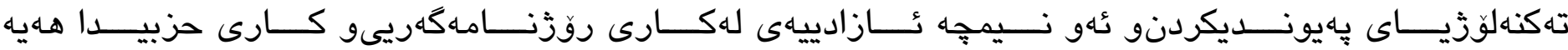

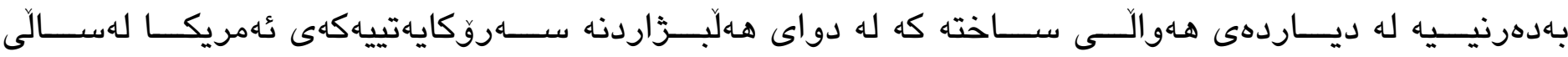

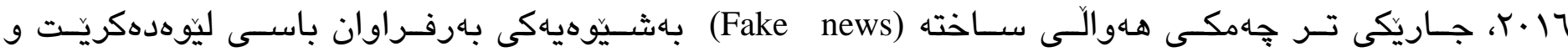

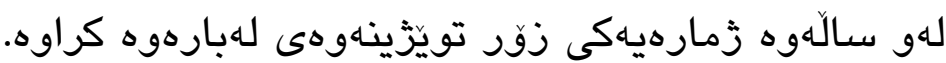

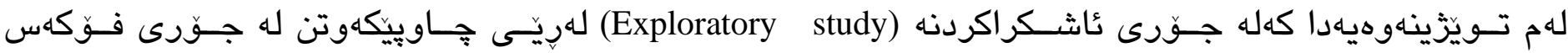

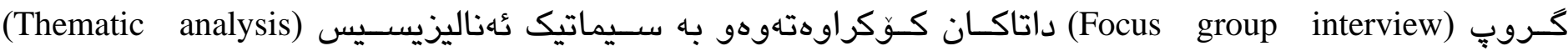

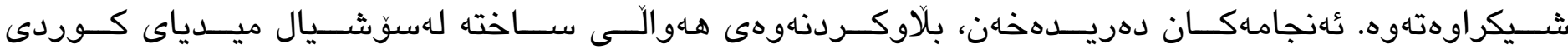

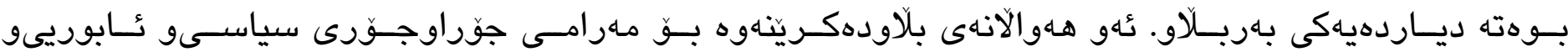

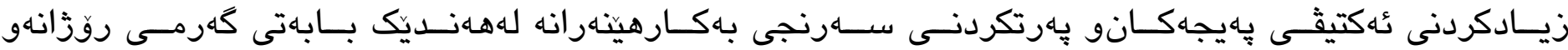

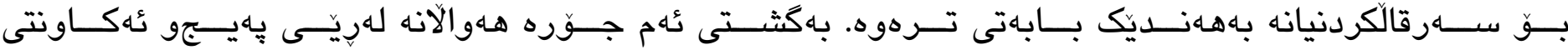

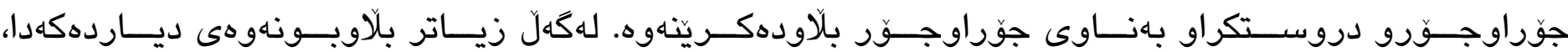

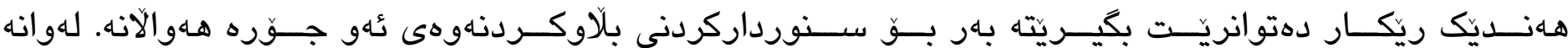




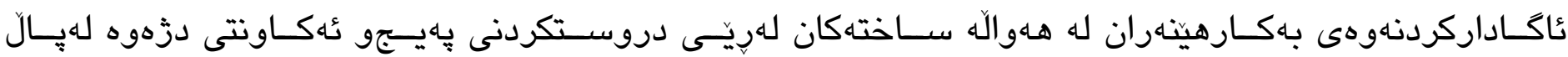

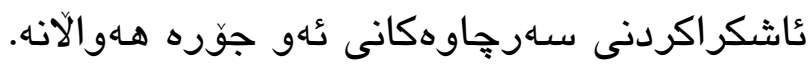

كايله وشُهكان: هـوالى ساخته، سوّشيال ميديا ، تهنكزَهى سياسيى، هـريّمى كوردستان، جههواشهكاريى، بهردنكاريوونهوه.

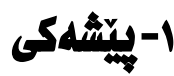

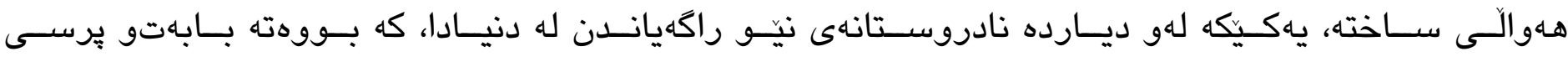

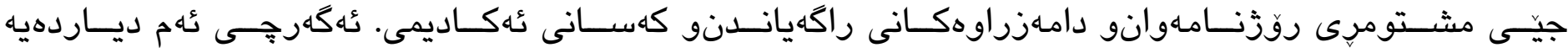

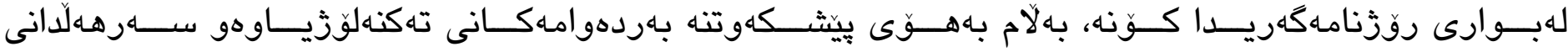

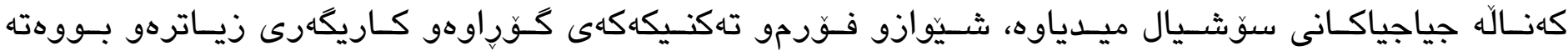

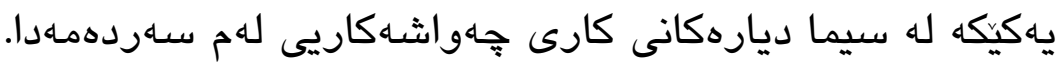

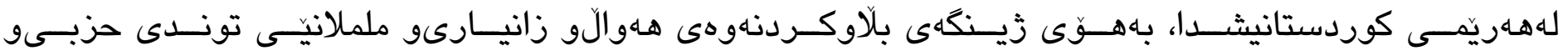

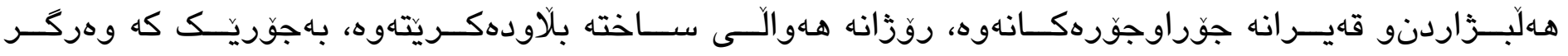

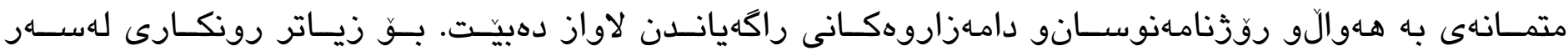

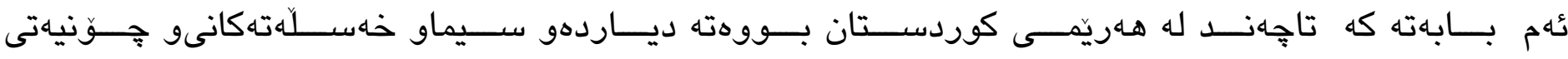

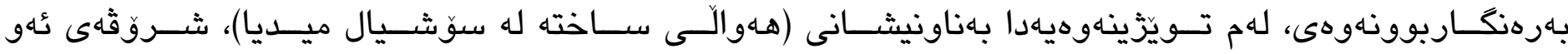
بابهته دهكريت.

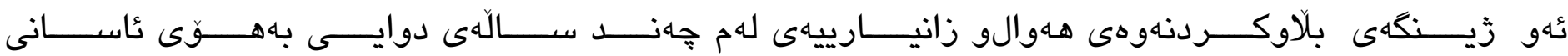

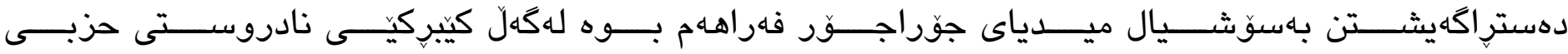

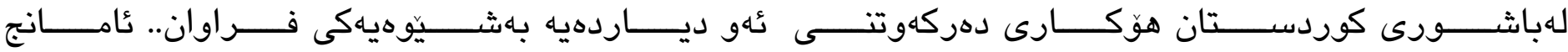

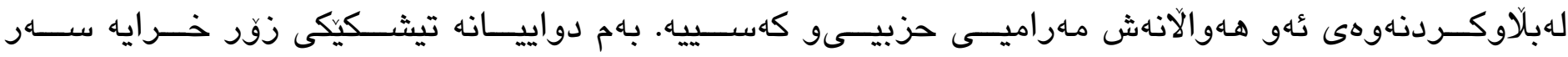

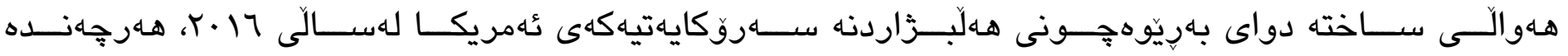

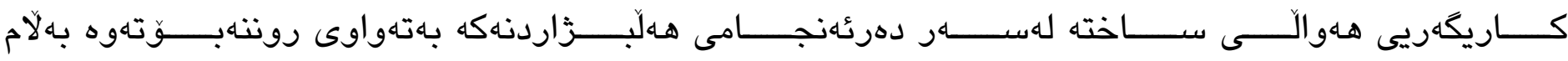

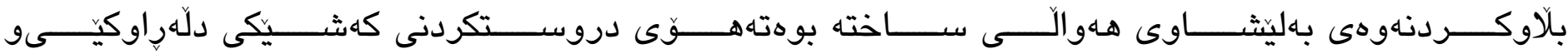
جهواشهكاريى. 


\section{r- تويرّزينهوهكانى بيّشُووتر}

\section{ب-1: جهمكى هلووالّى ساخته}

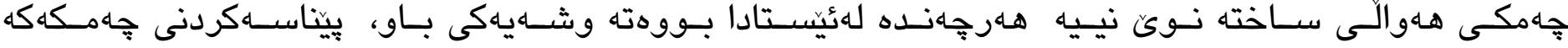

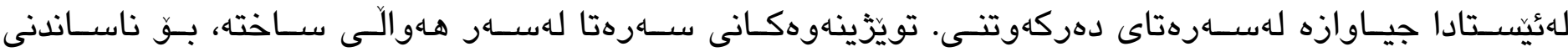

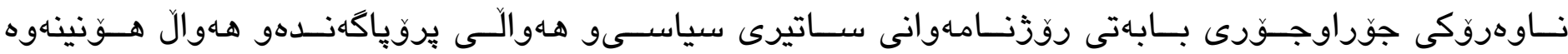

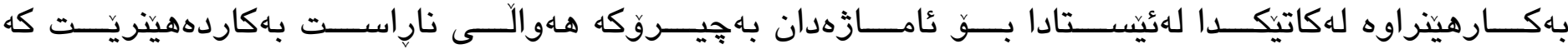

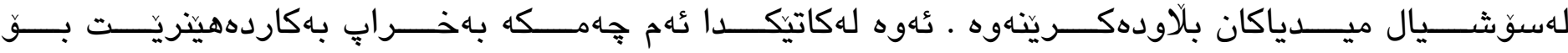

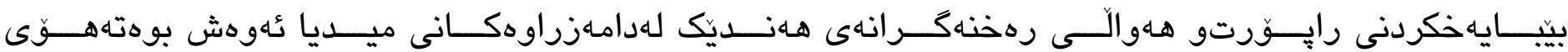

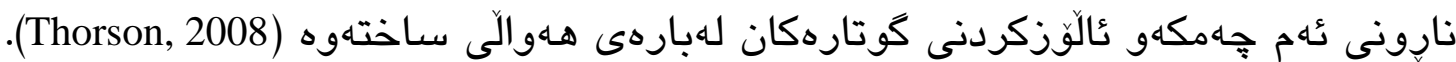

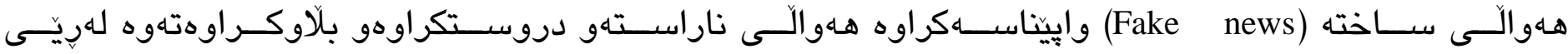

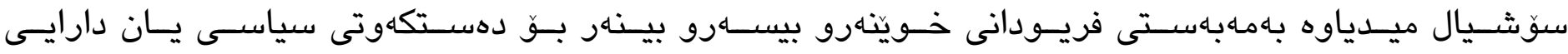

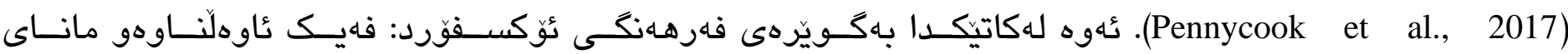

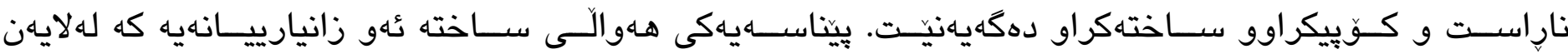

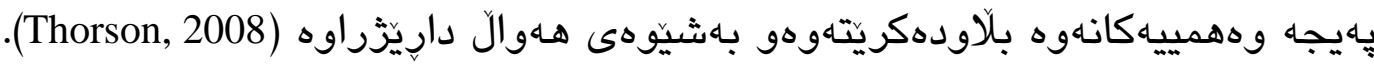

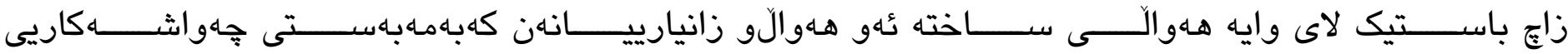

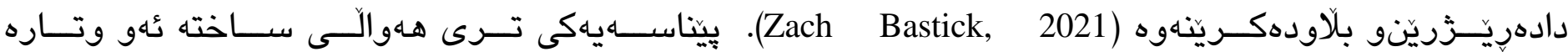

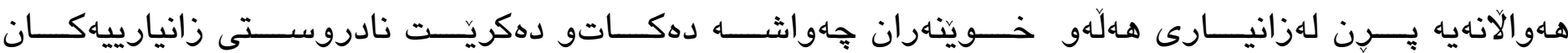
بسهالمينزيتيت (Allcott and Gentzkow, 2017).

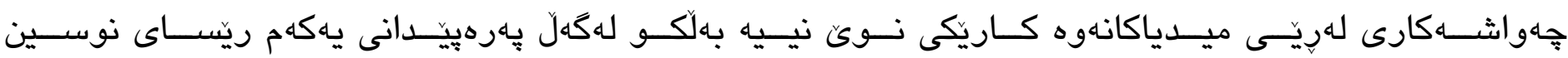

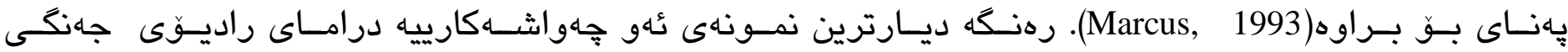

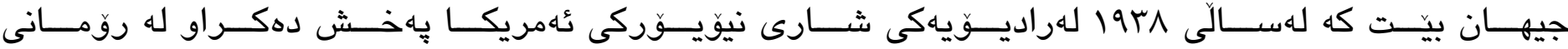

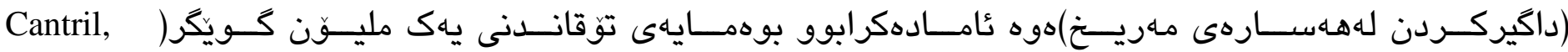
.2005

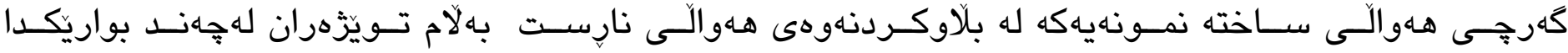

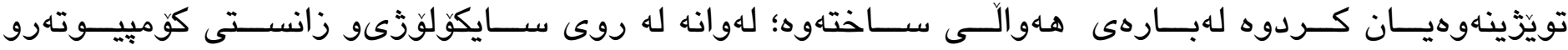

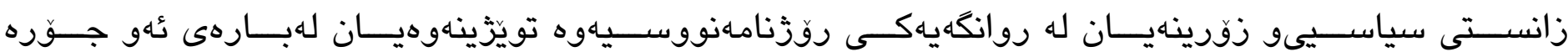
هـالذه نوسيوه (Wardle, 2017).

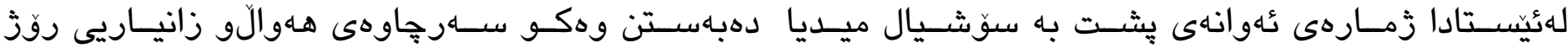

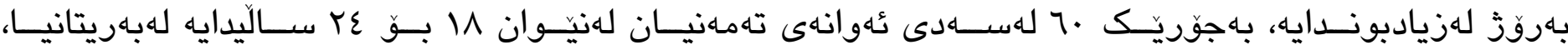

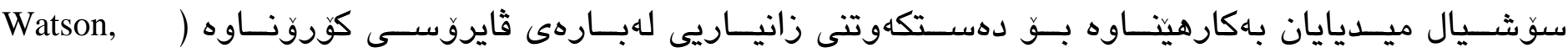

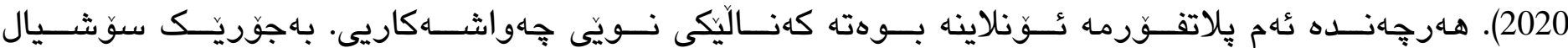




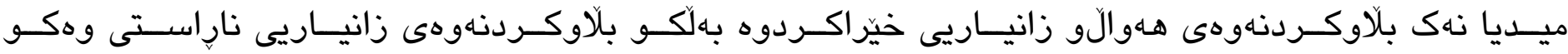

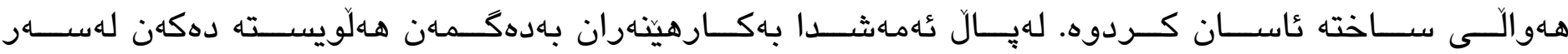

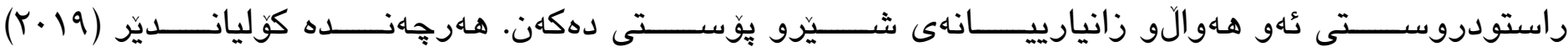

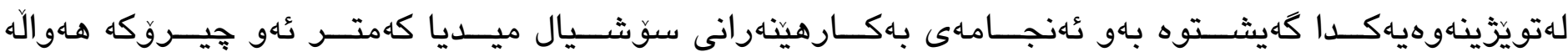

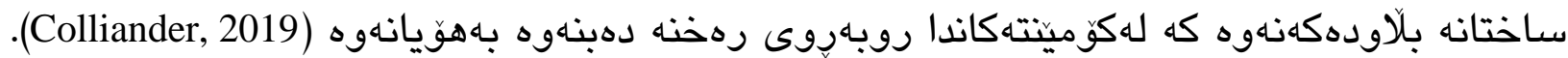

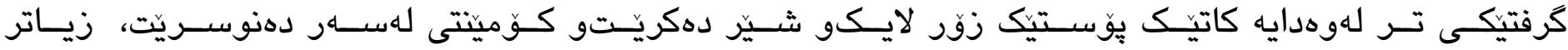

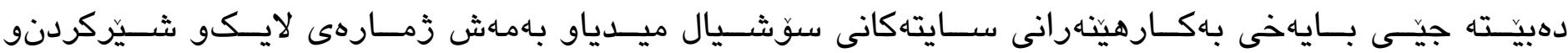

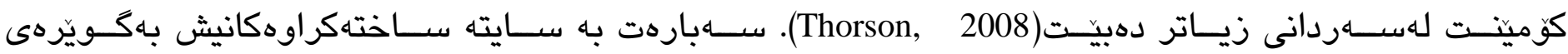

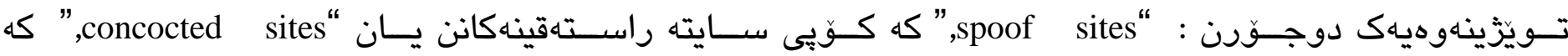

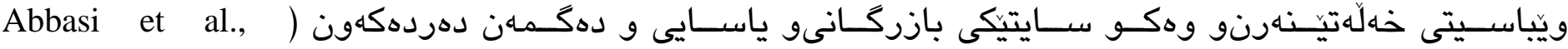
. (2010

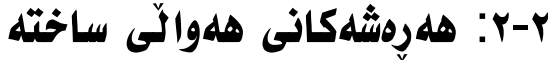

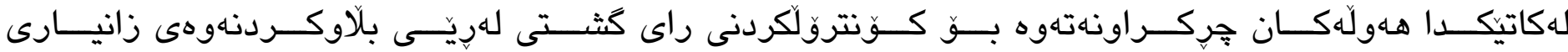

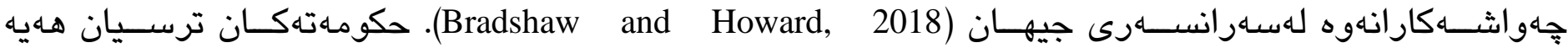

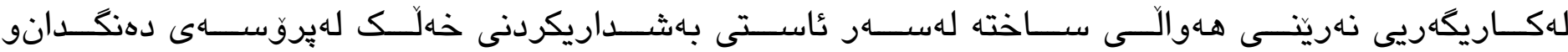

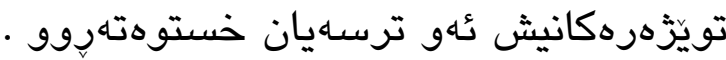

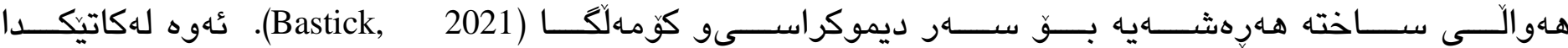

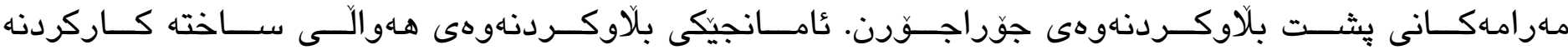

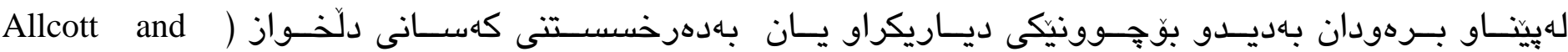

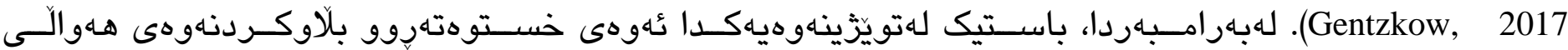
ساخته لهيَّى روانكاهيهى ئونلاينهوه بو مهرامى سياسيىو دهستكهوتنى داراييه (Bastick, 2021).

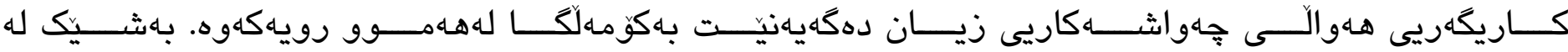

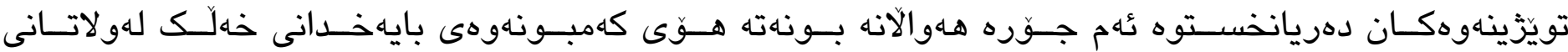
جيهان باهبهتنى ماسكو يابهندبوون به دوركهوتناهوهى كومالآياتى (Mattiuzzi and Lippi, 2020).

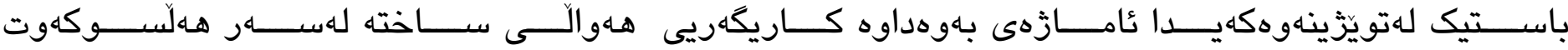

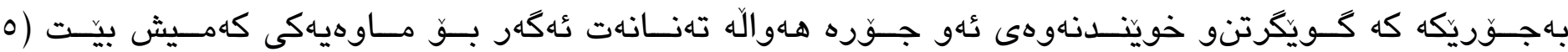

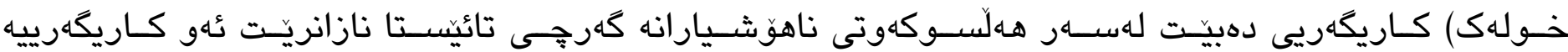

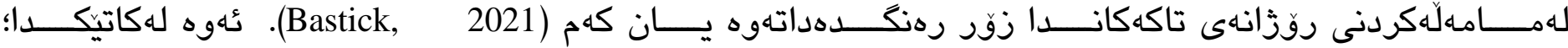

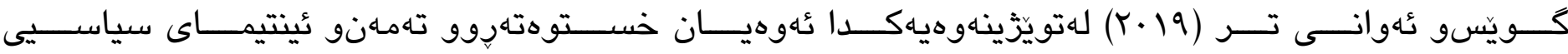

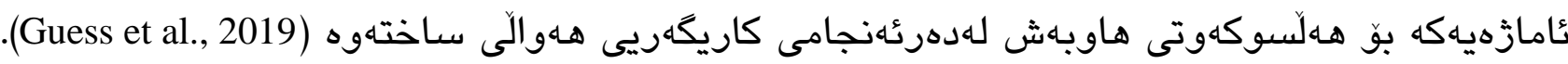




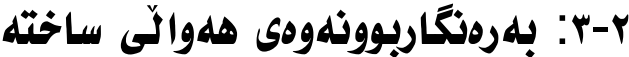

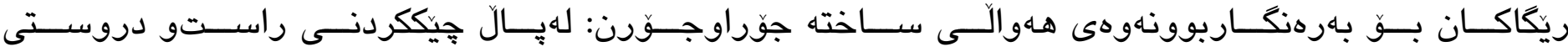

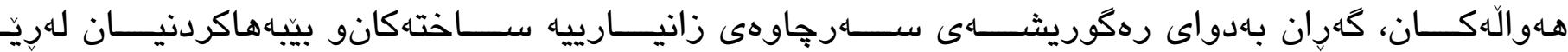

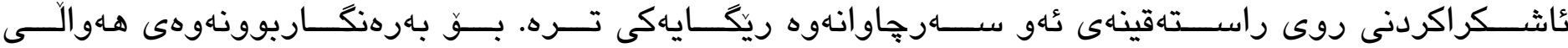

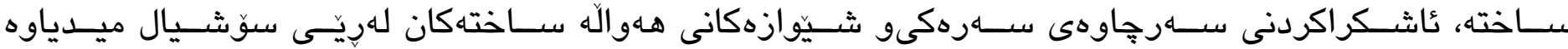
كاريكى كرنكه(Mele et al., 2017).

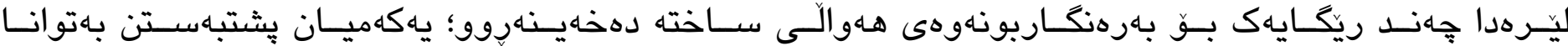

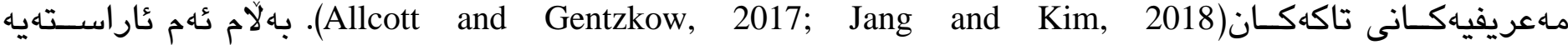

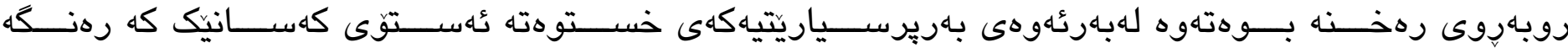

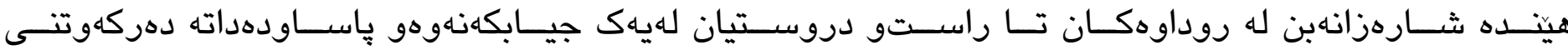

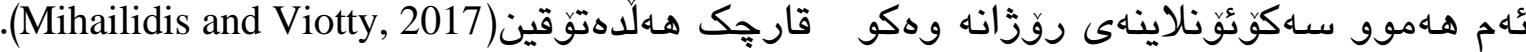

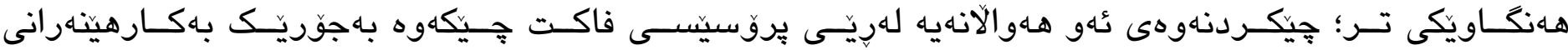

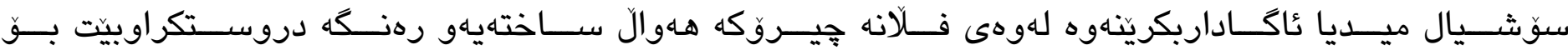

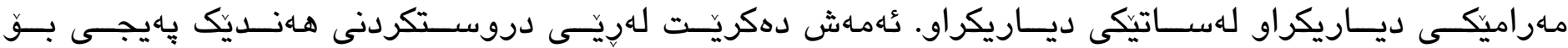

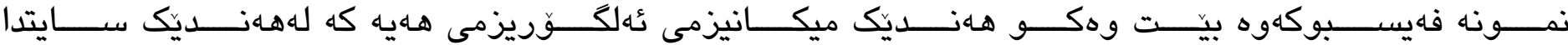

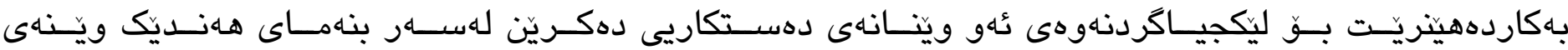

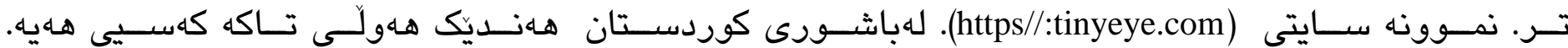

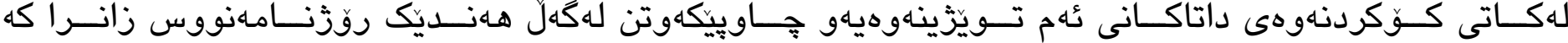

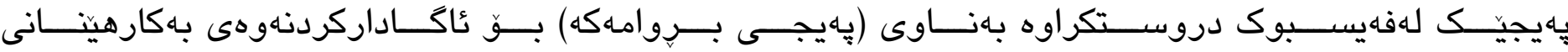

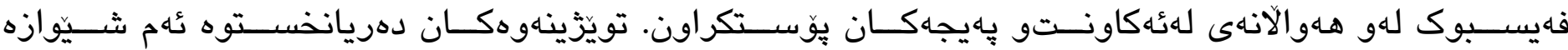

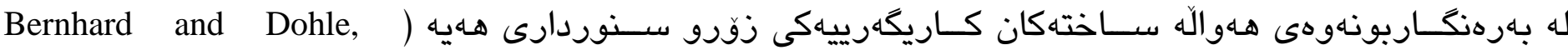
. (2015

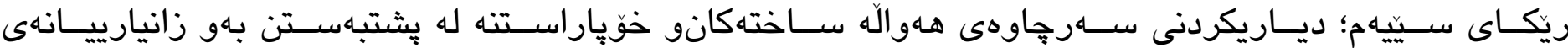

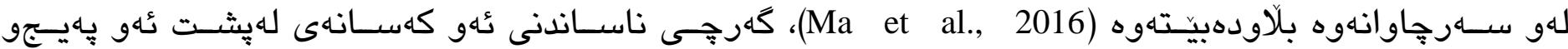
ئهكاونتانهوهن كاريكى ئاسان نيياه.

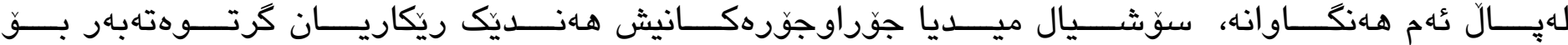

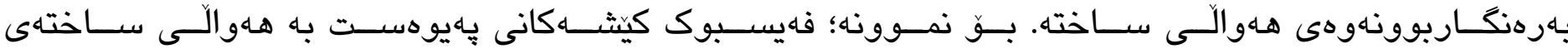

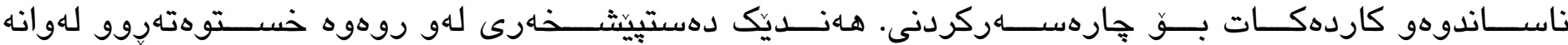

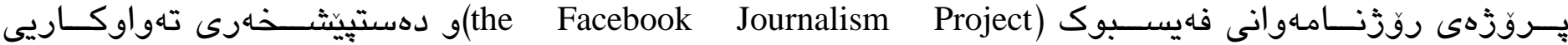

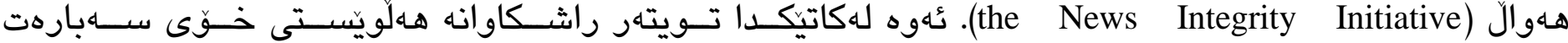

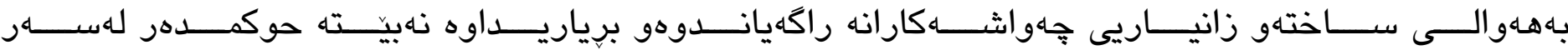

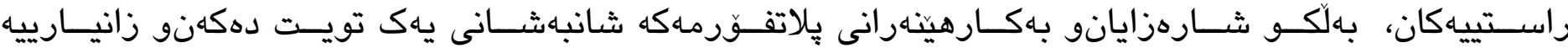




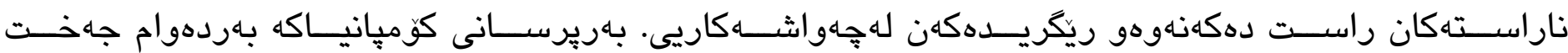

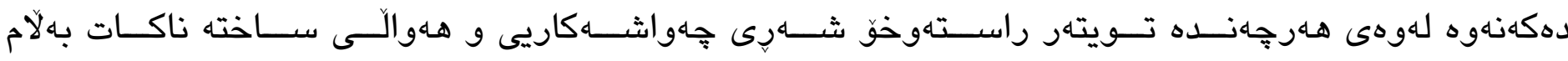

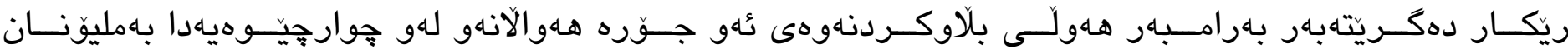

هـأزمارى داخستوه (Verison, 2021).

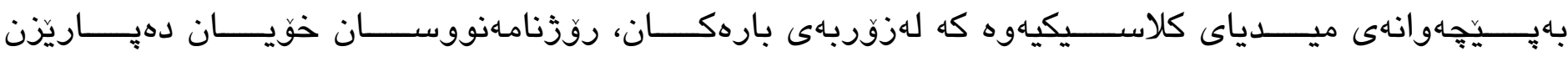

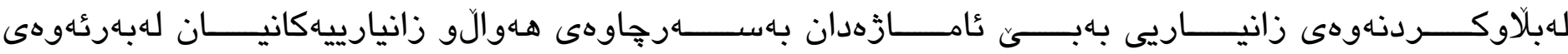

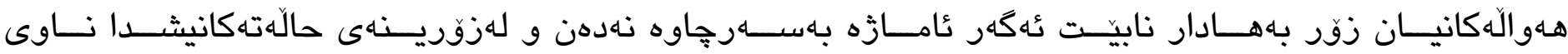

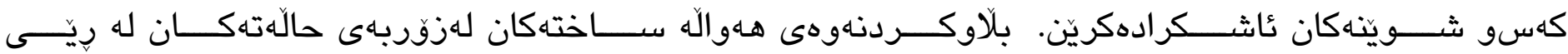

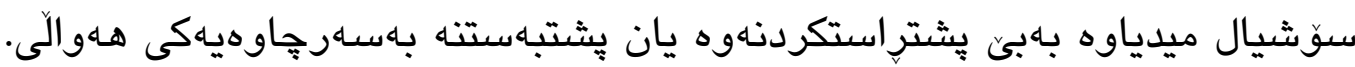

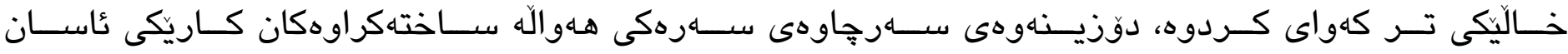

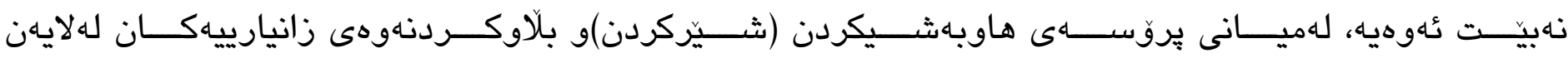

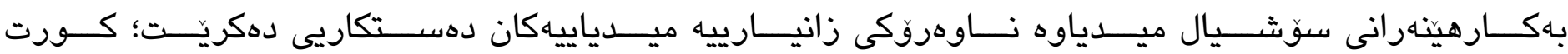

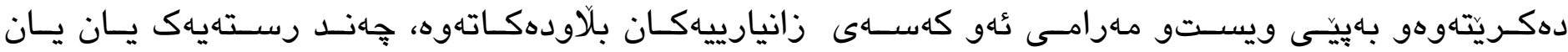

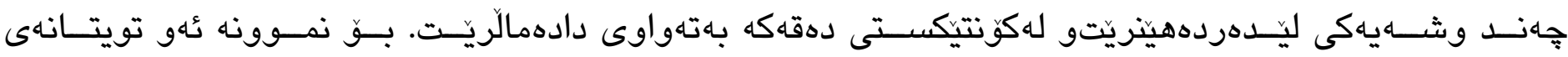

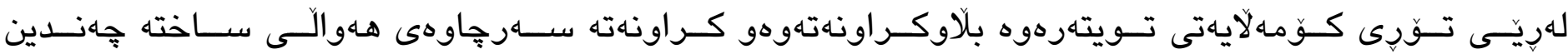

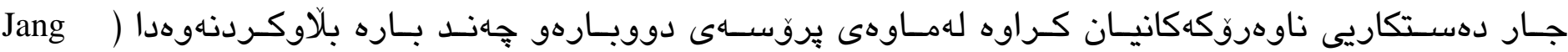
.(ael., 2018

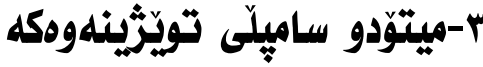

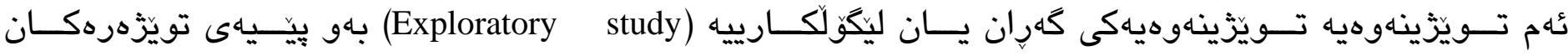

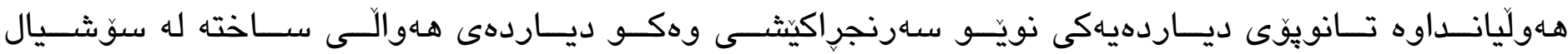

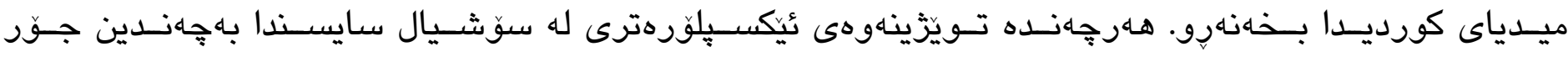

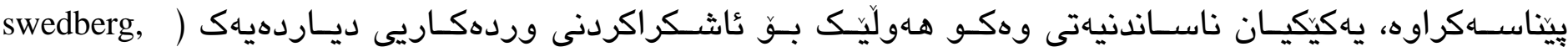

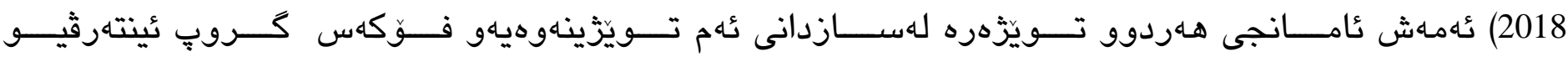

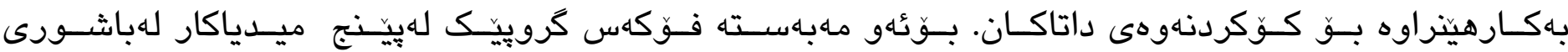
كوردستان بيّكهينزراوه.

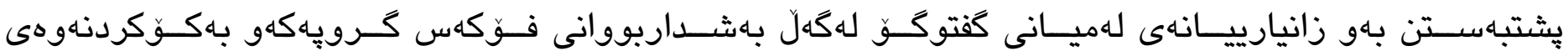

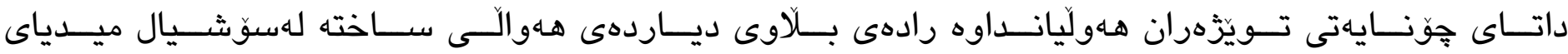

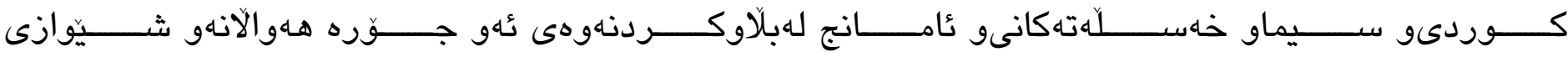

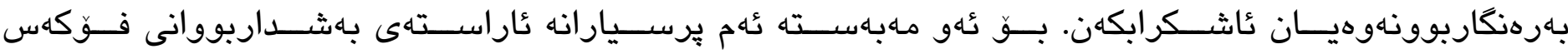
كروب ئينتهرثيوهكه كراوه: 


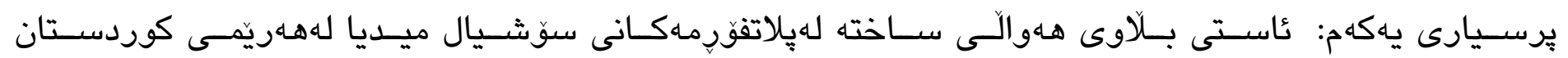
جهنده؟؟

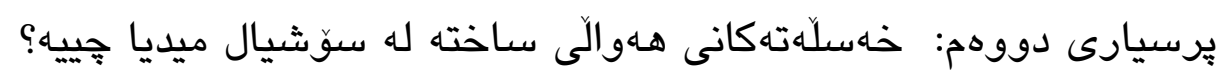

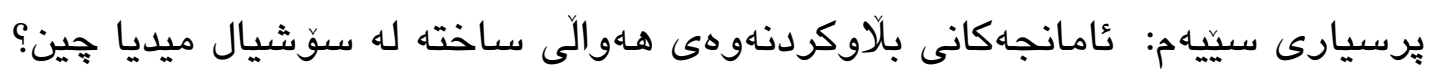

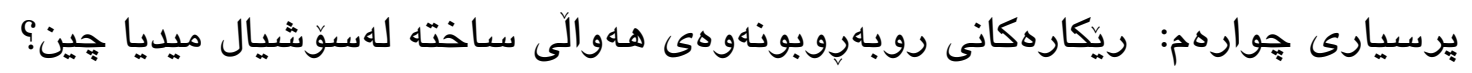

\section{ع-شيكردنهوهى داتا}

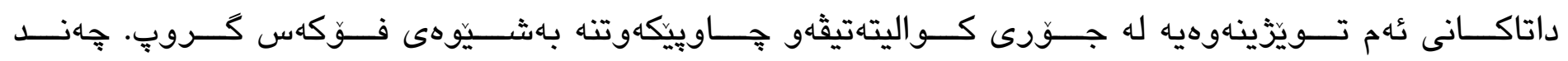

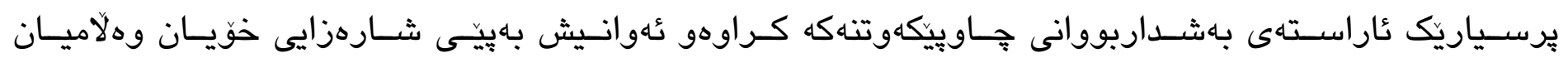

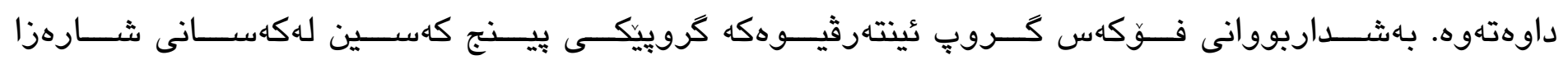

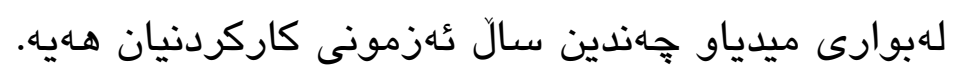

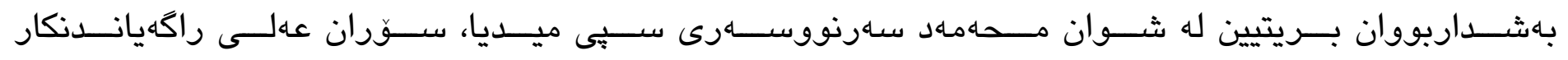

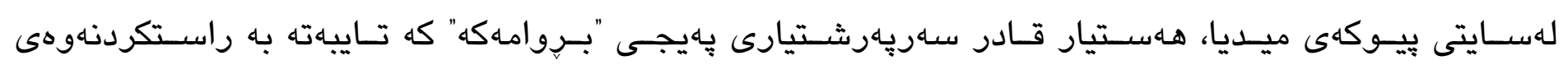

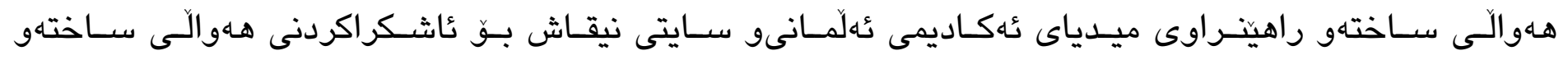

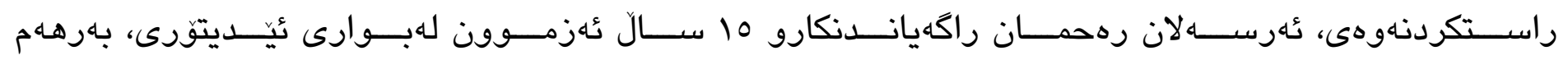

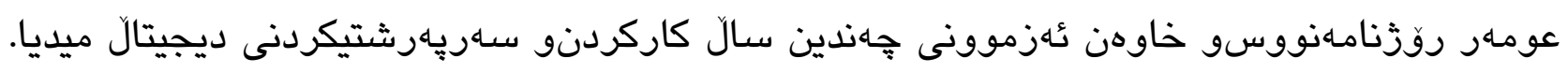

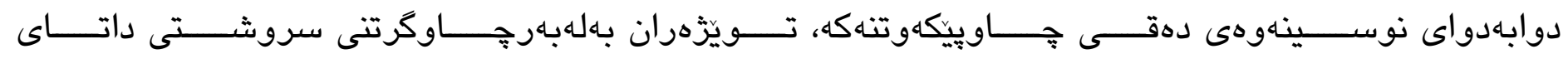

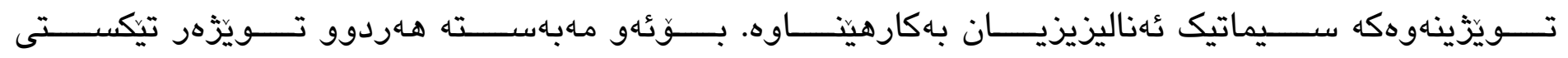

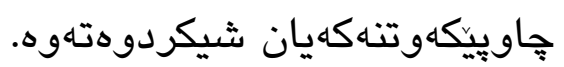

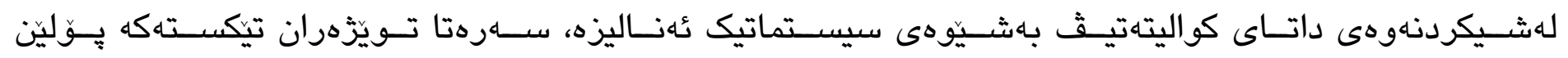

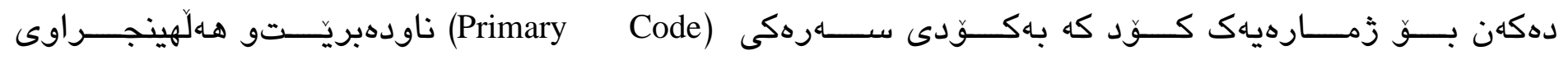

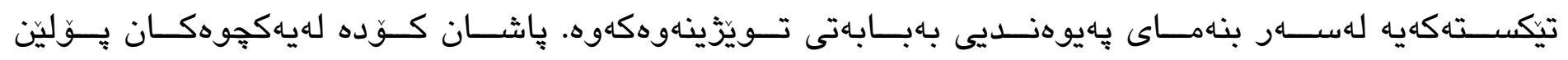

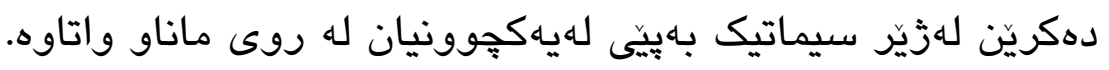

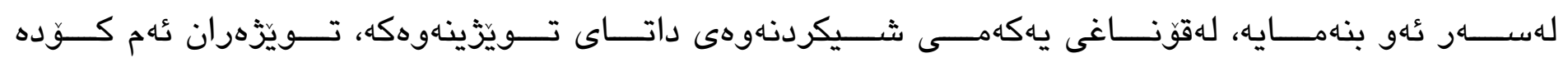

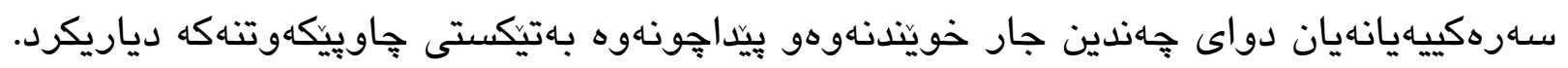

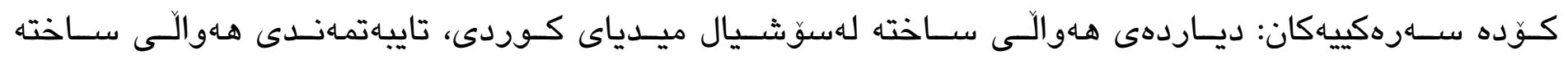

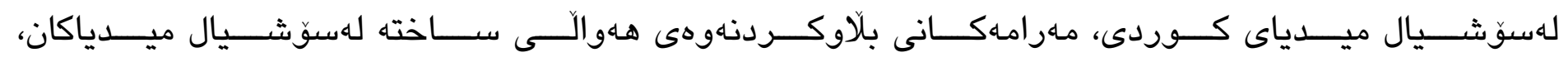

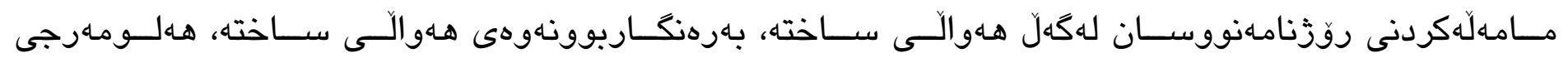

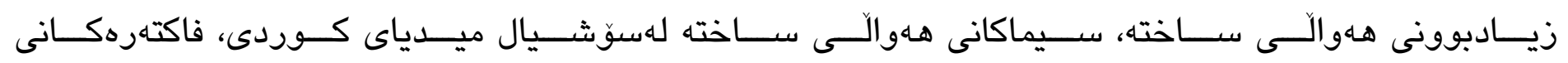

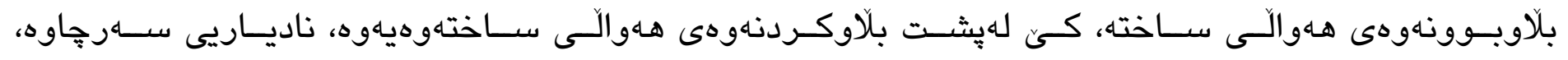

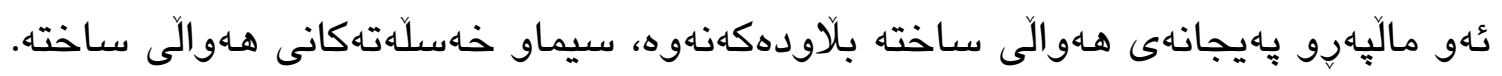




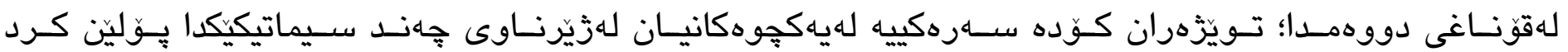

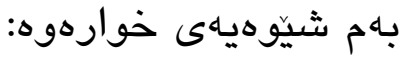

\begin{tabular}{|c|c|}
\hline سيماتيك (Thematic) & كودىى سـرهكيى(Primary Code) \\
\hline \multirow{3}{*}{ دياردهى هـوالى سـاخته } & دياردهى هـوالّى ساخته لهسوشيال ميدياى كوردى \\
\hline & هـلومـرجى زيادبوونى هـهوالى ساخته \\
\hline & فاكتهرهكانى بلاّوبوونهوهى هـاهوالى ساخته \\
\hline \multirow{4}{*}{ سيماكانى هـاهوالى ساخته } & تايبهتمهندى هـهوالّى ساخته لهسوشيال ميدياى كوردىى \\
\hline & سيماكانى هـوالَى ساخته لهسوّشيال ميدياى كوردى \\
\hline & سيماو خهسلاكتهكانى هـهوالى ساخته \\
\hline & نادياريى سـرجهاوه \\
\hline \multirow{3}{*}{ 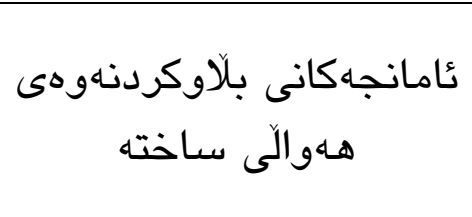 } & ماهرامهكانى بلاّوكردنهوهى هـوالَى ساخته لهسوّيال ميديا \\
\hline & كئ لهيشت بلاوكردنهوهى هـوالَى ساختهوهيهوه \\
\hline & 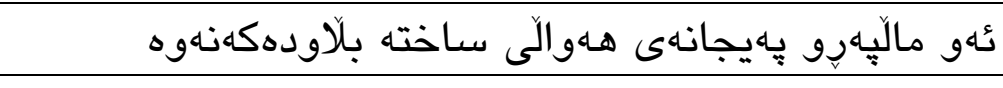 \\
\hline \multirow{2}{*}{ بهرهنكاربوونهوهى هـاهوالى } & 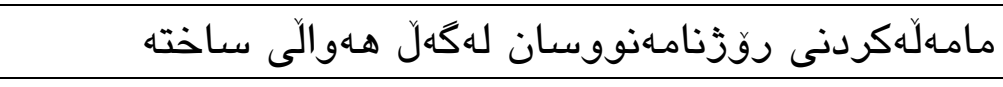 \\
\hline & بهرهنكاربووناهوهى هـاهوالى ساخته \\
\hline
\end{tabular}

0-ئلنجاملكان

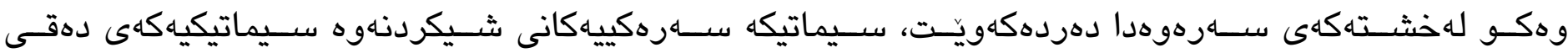

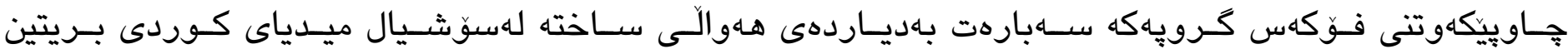

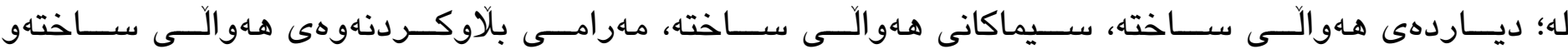

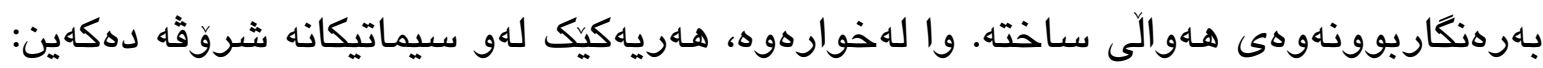

\section{ه-ا: دياردهى هلووالّى ساخته}

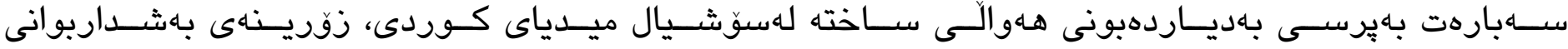

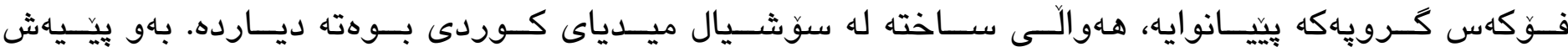

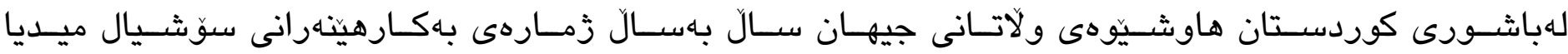

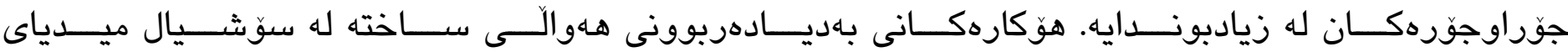

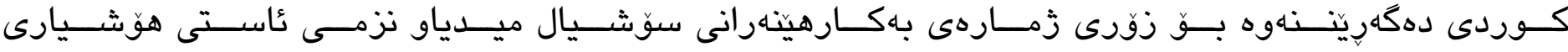

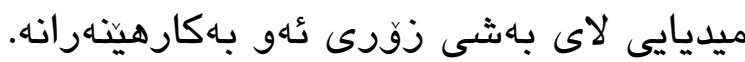




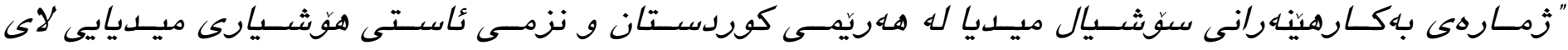

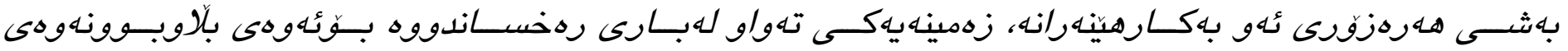

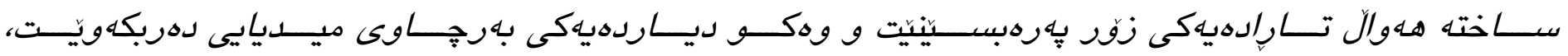

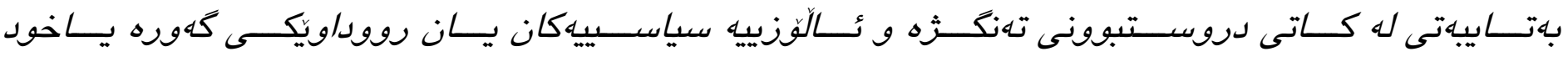

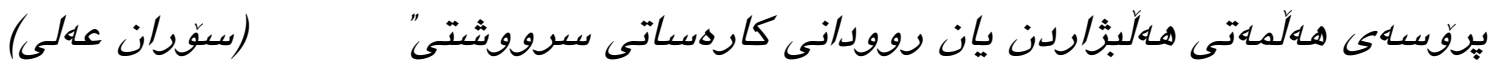

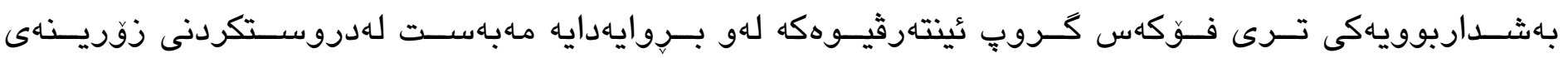

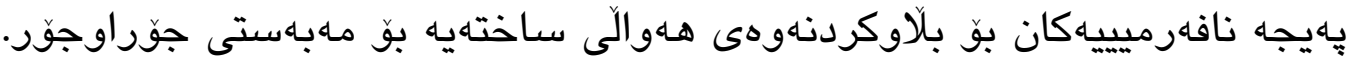

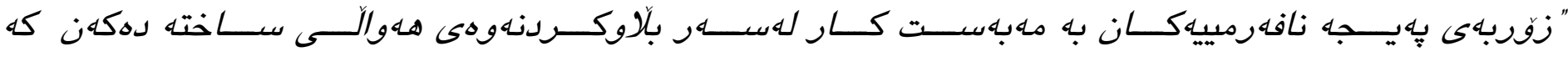

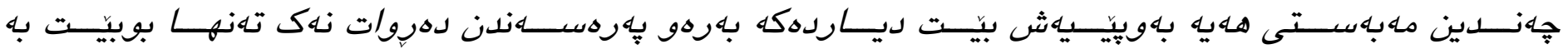
لمارده

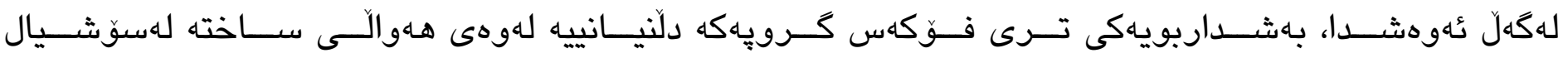

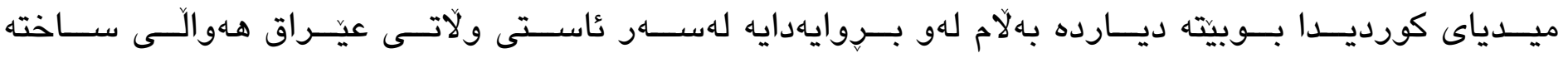
ل لهوّشيال ميدياكان بوهته ديارده.

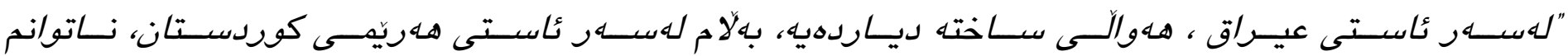

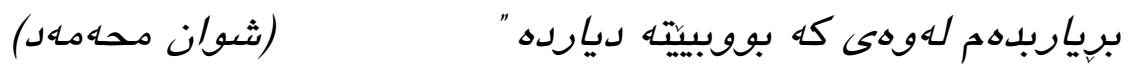

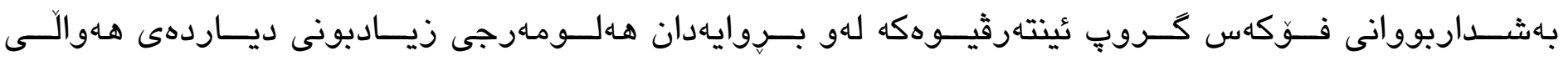

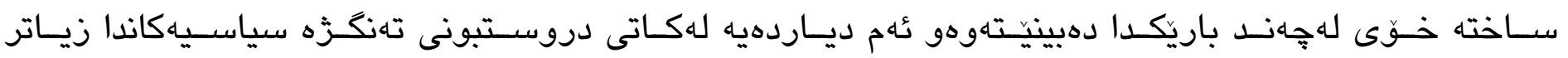
دهردهكهويت.

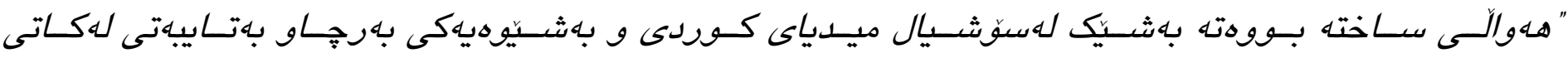

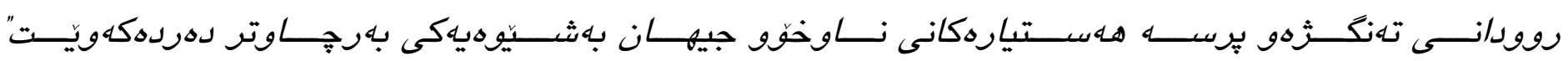
(ئه رسهلان رهحمان)

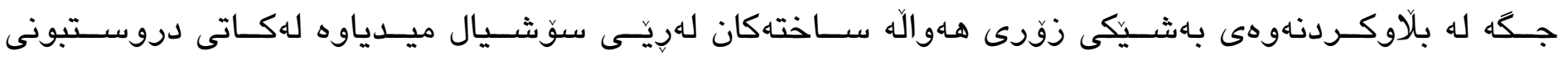

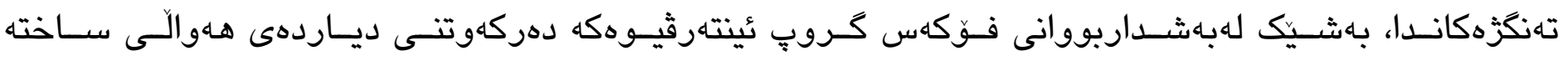

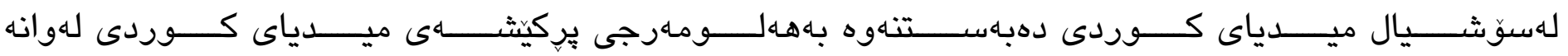

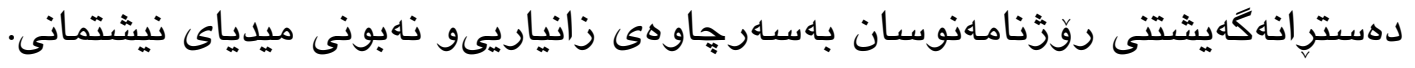




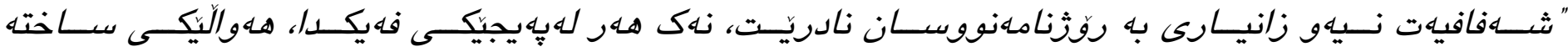

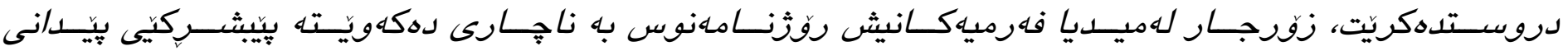

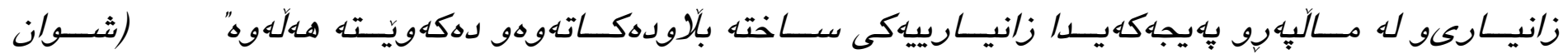

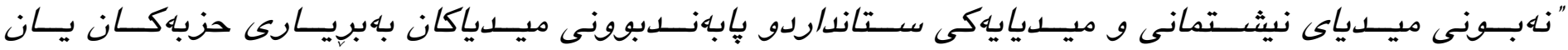

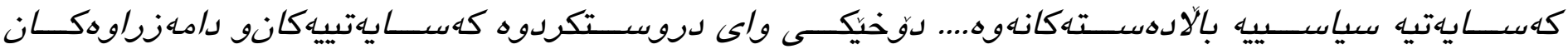

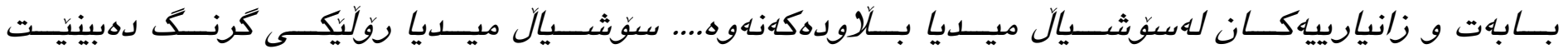

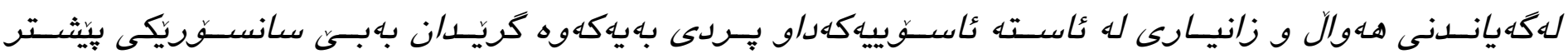

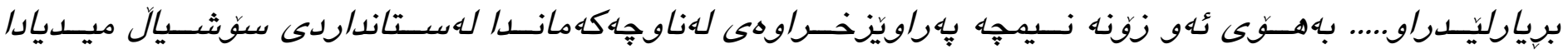

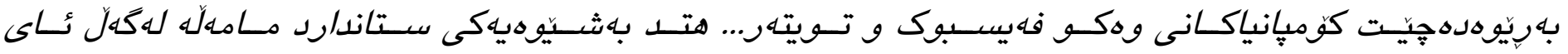

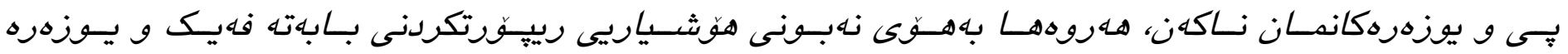

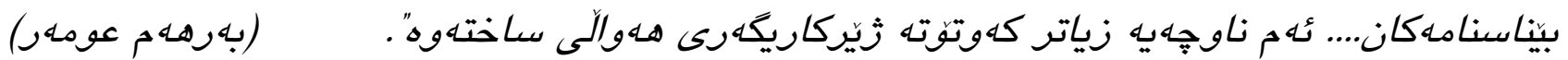

\section{0-Y- سيماكانى هلوالّى ساخته له سوّشيال ميلدياى كوردى}

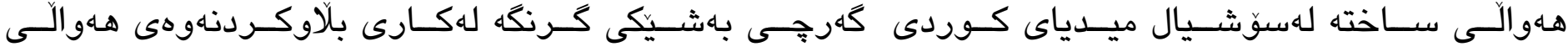

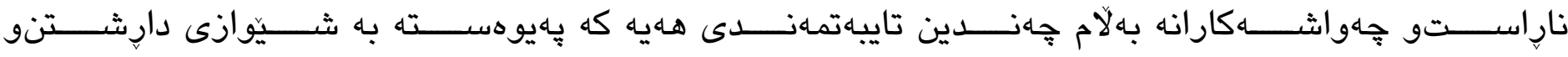

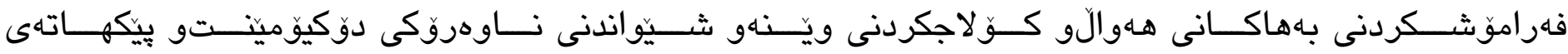

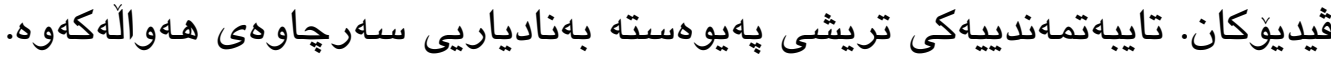

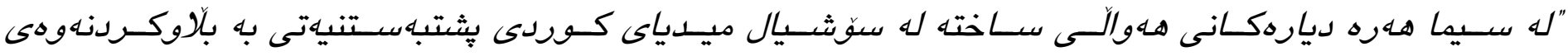

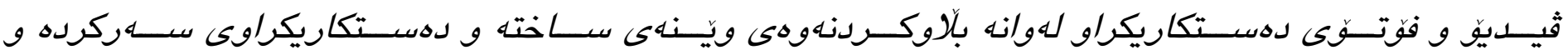

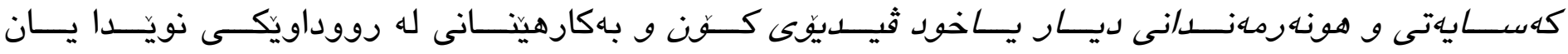

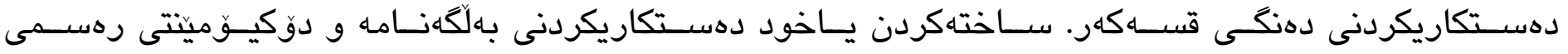

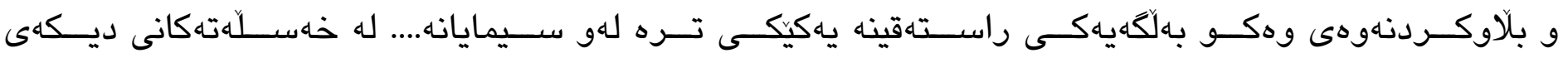

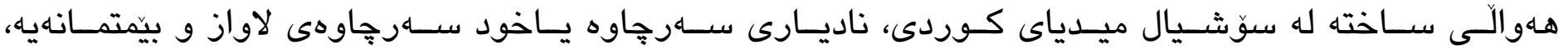

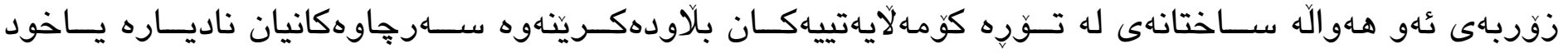

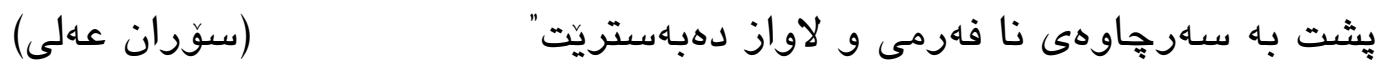

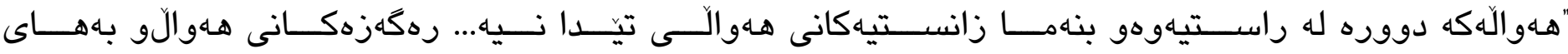

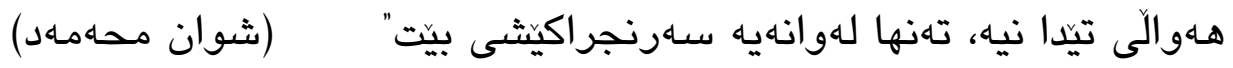




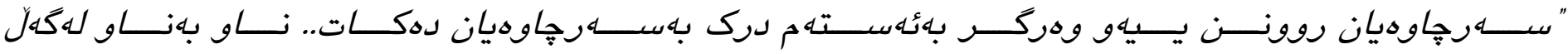

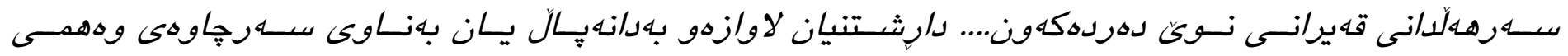

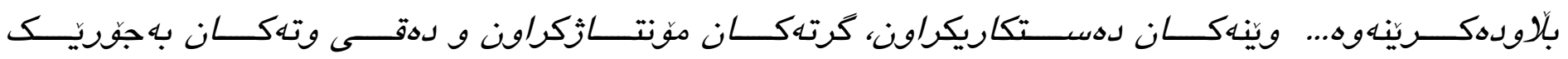

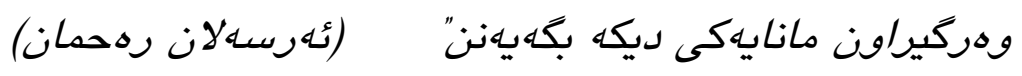

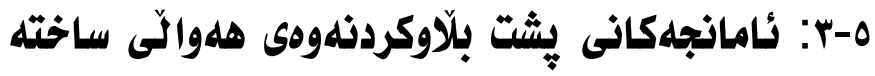

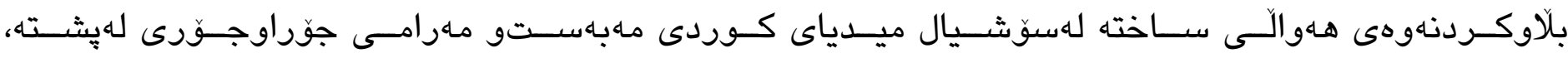

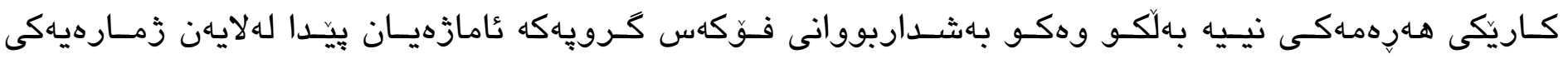

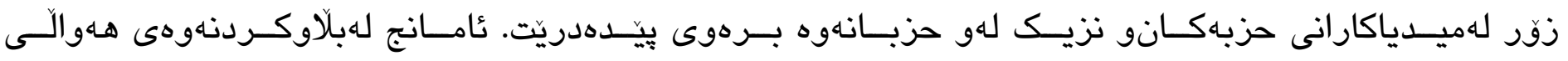

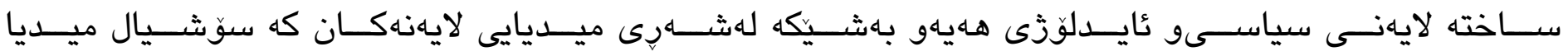

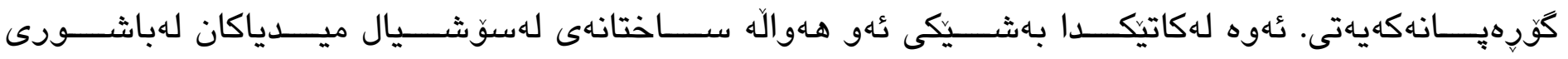

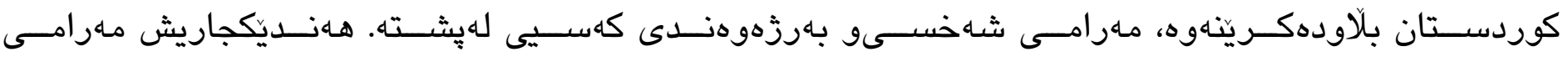

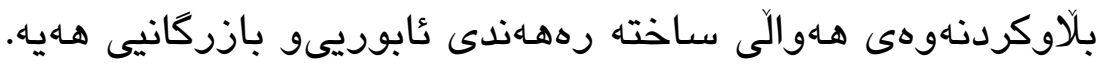

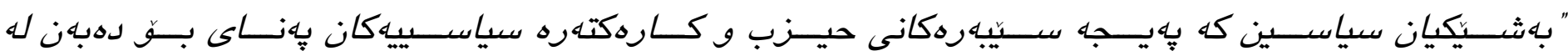

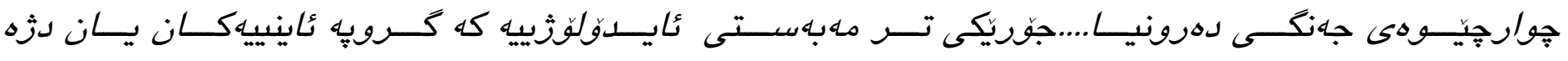

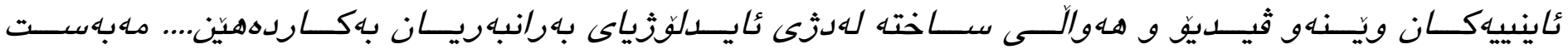

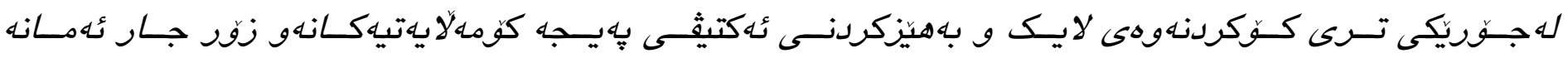

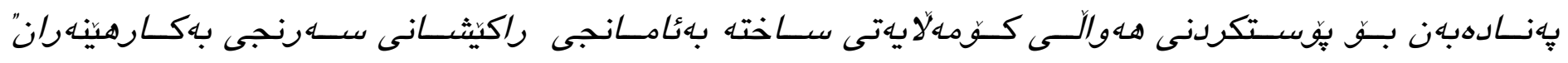
(هـهتيار تادر)

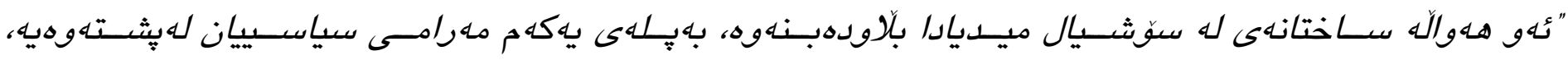

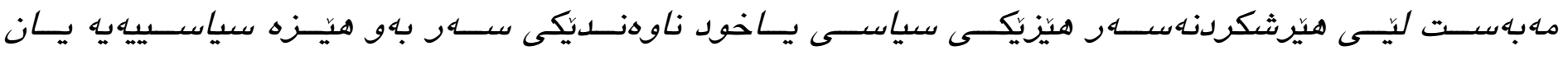

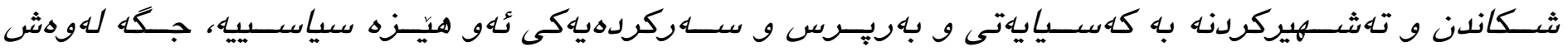

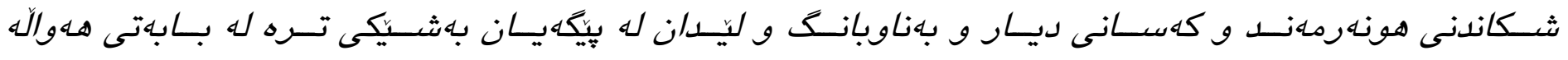

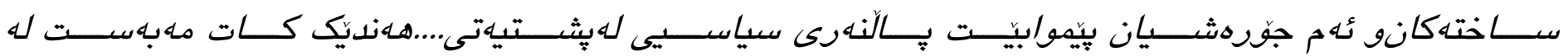

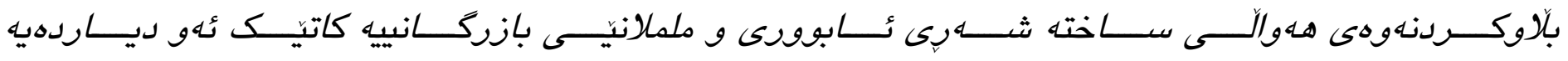

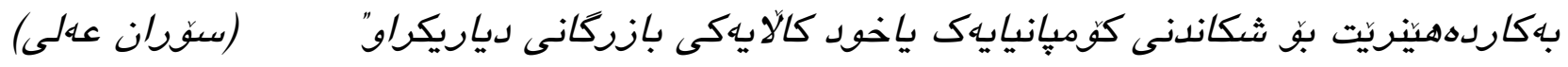




\section{ه-\}: بلهرهنًاربوونلوهى هلهواذّى ساخته}

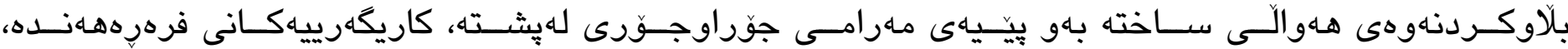

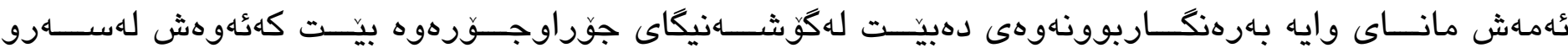
باباتى تويَزينهوهكهى ئيماهيه.

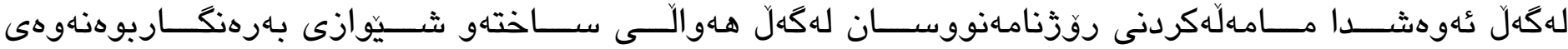

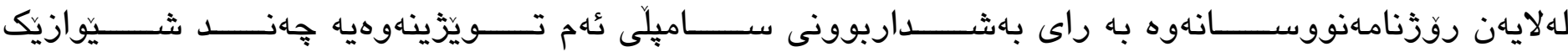

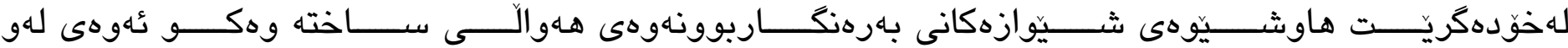

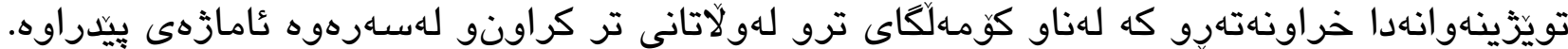

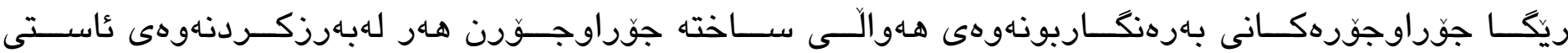

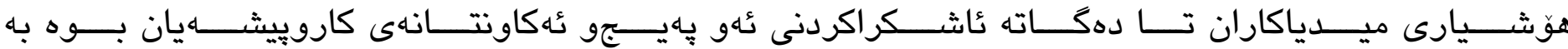

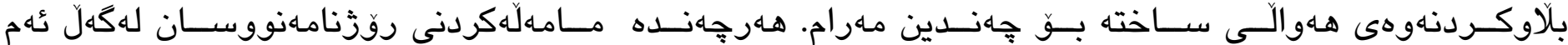

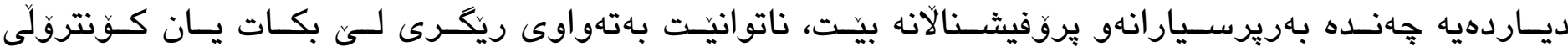

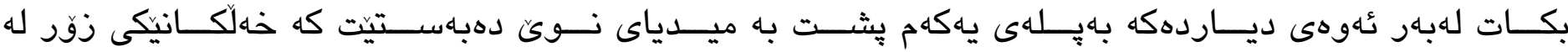

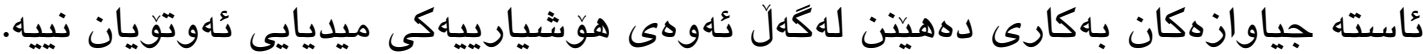

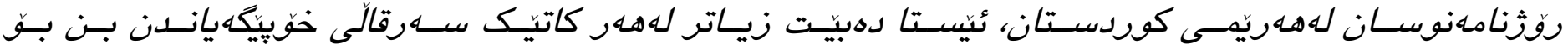

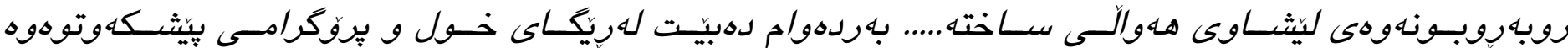

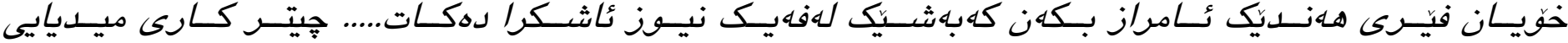

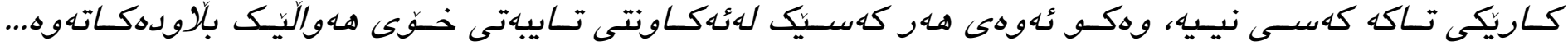

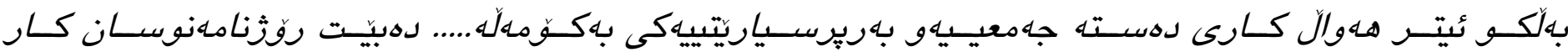

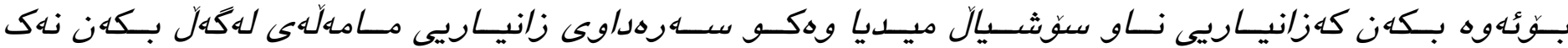

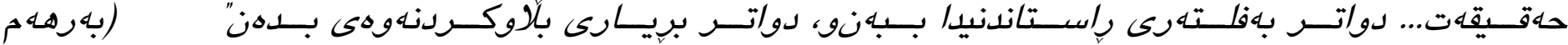

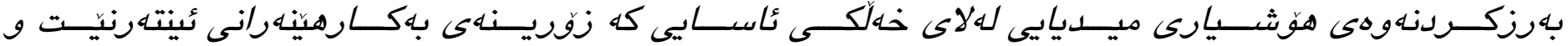

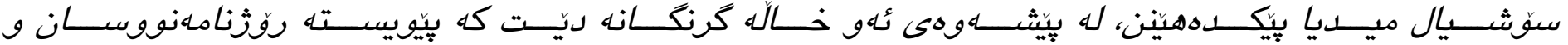

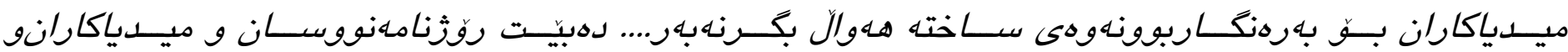

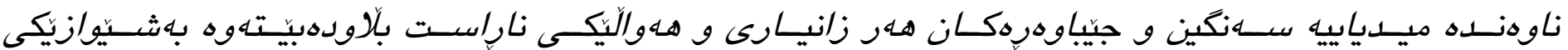

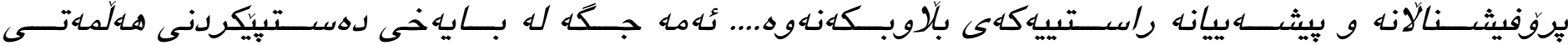

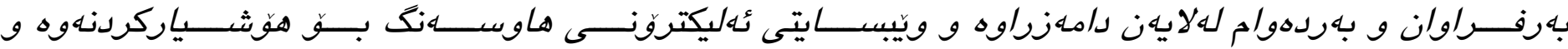

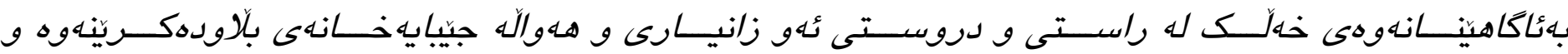


راسـتكردنهوهى هـر ناراسـتى و جهواشــهارى و سـاختهارييهك تييانــا. هـروههـا لروسـتكردنى سـايت

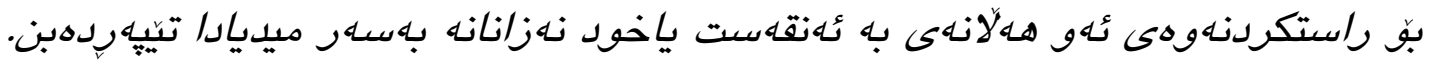

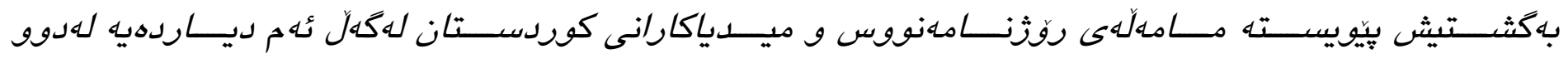

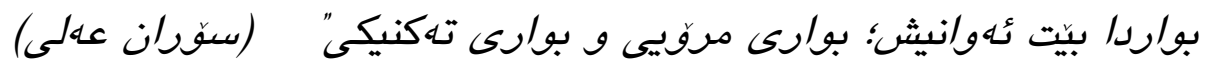

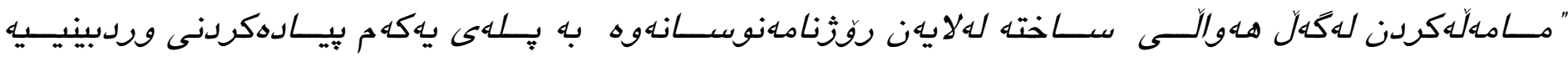

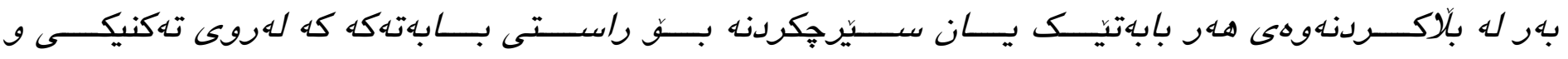

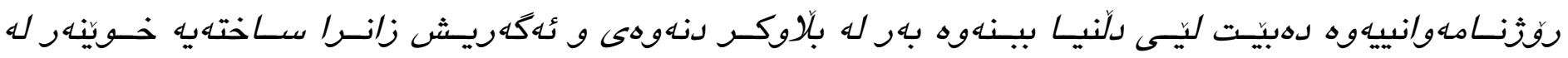

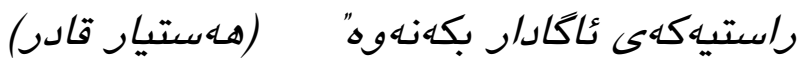

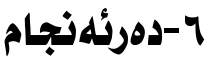

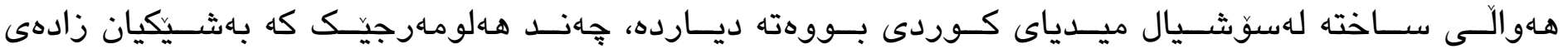

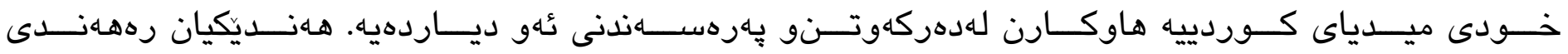

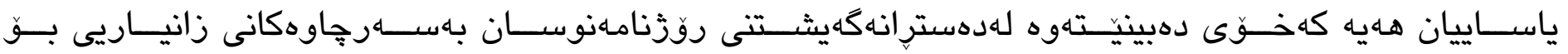

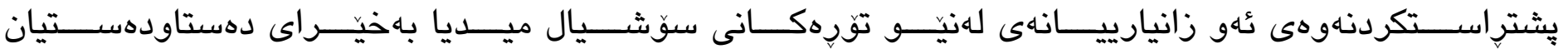

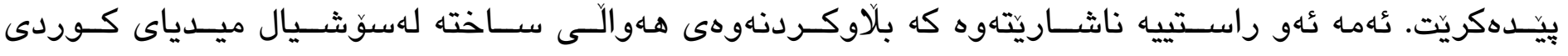

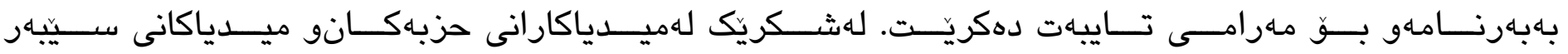

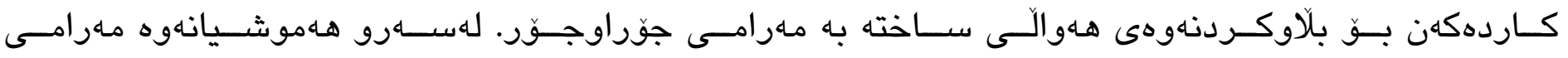

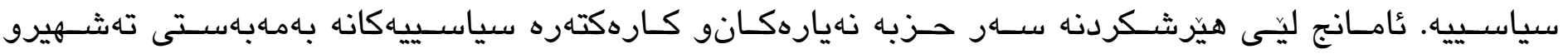

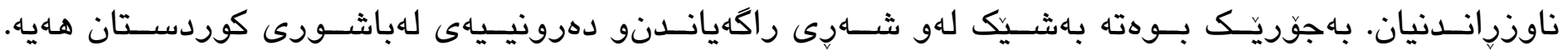

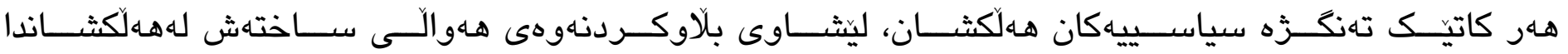

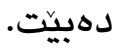

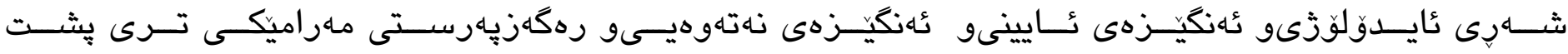

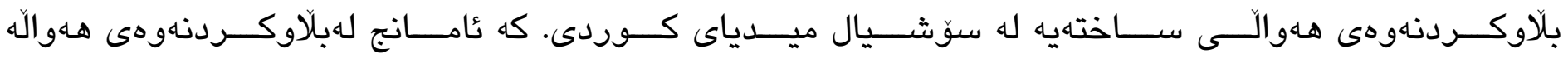

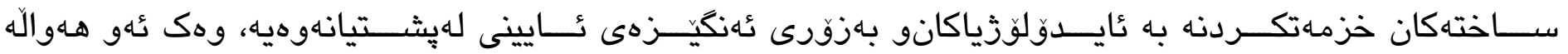

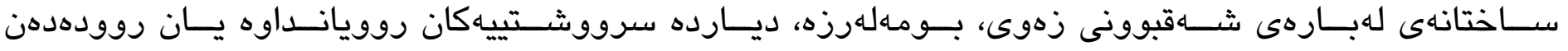

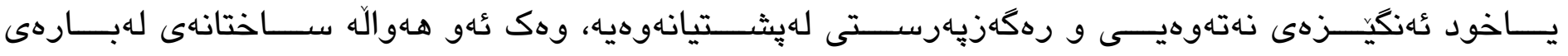

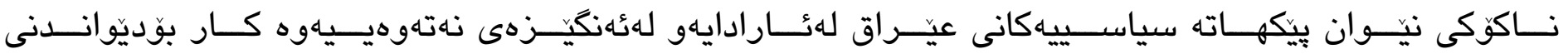

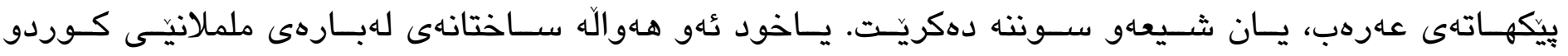
تورك لهتوركياو سووريا بلاودهكرينّهوه. 


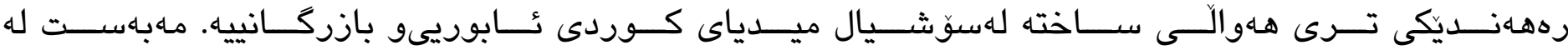

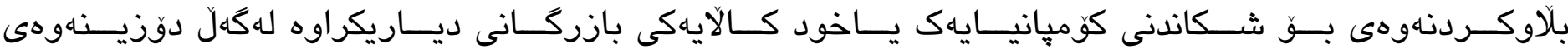

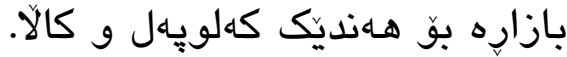

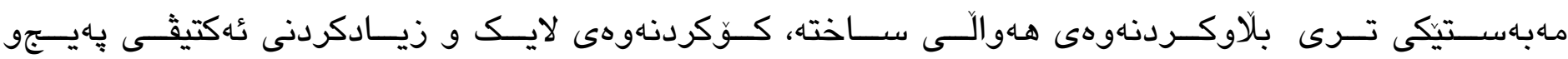

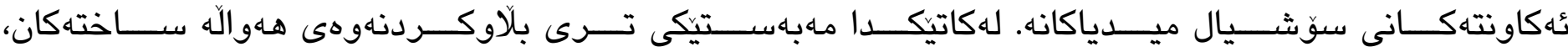

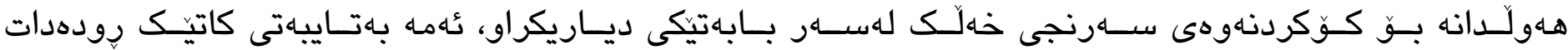

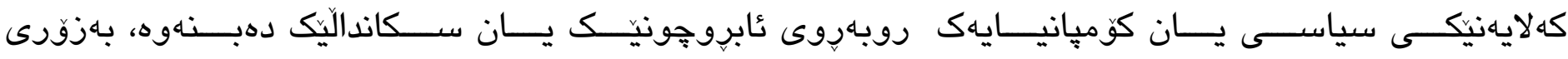

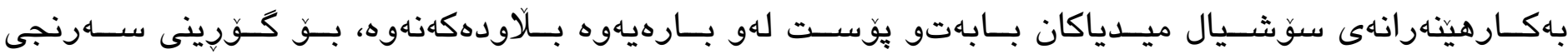

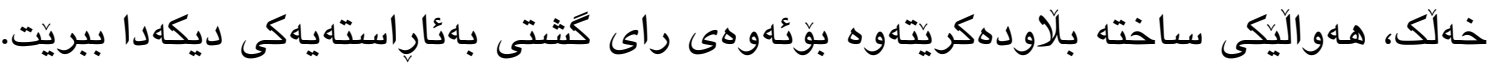

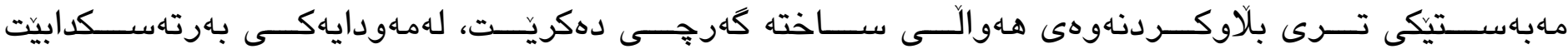

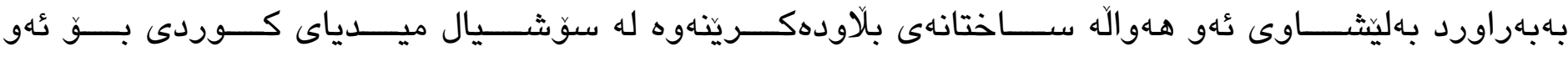

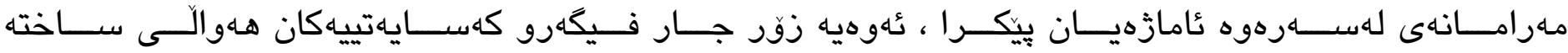

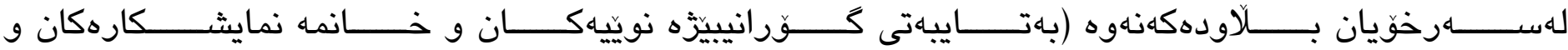

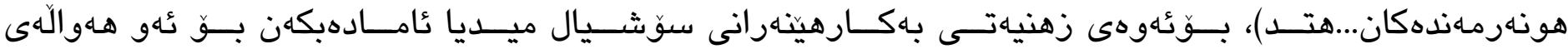

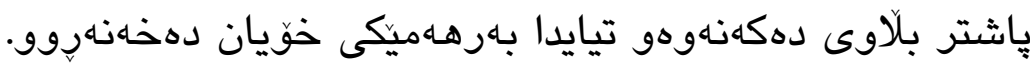

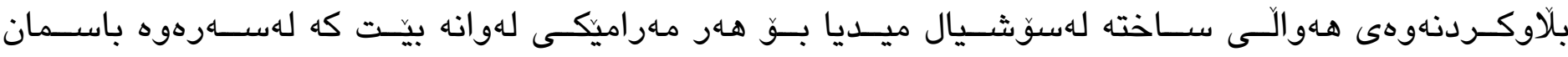

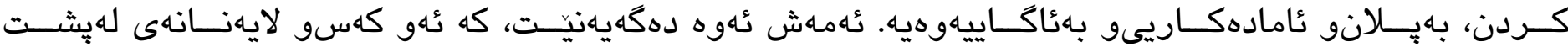

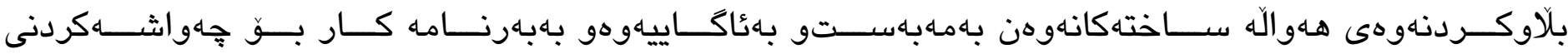

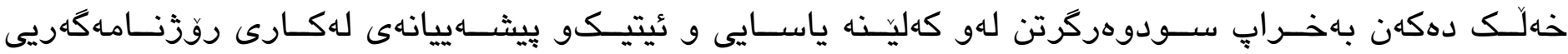
لهباشورى كوردستان هـيه.

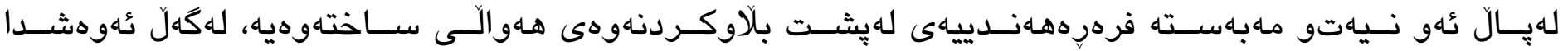

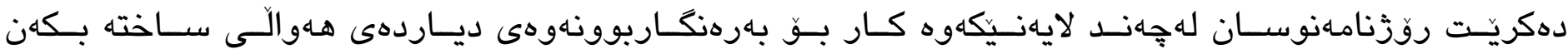

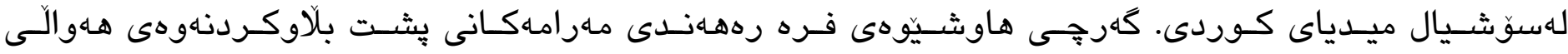

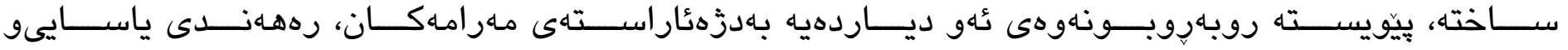

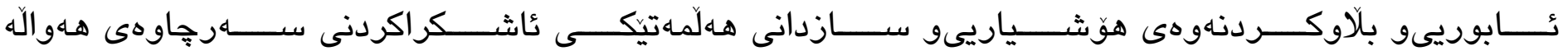
ساختهكان لهخو بكريّت

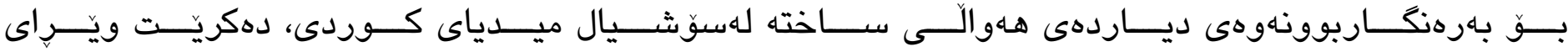

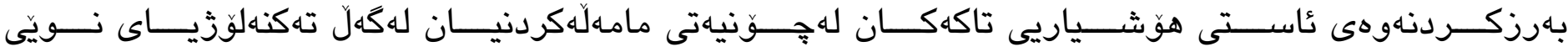

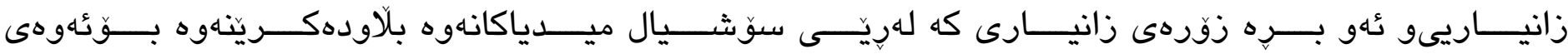

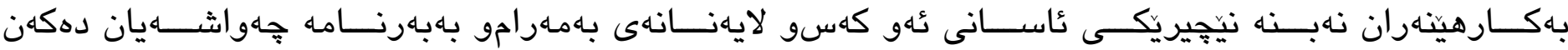

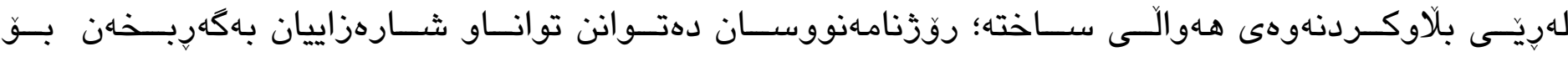

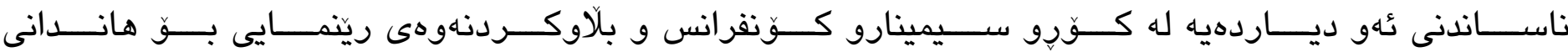




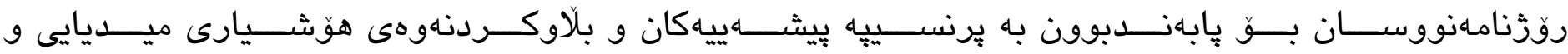

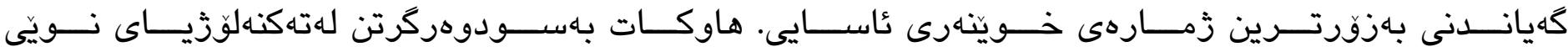

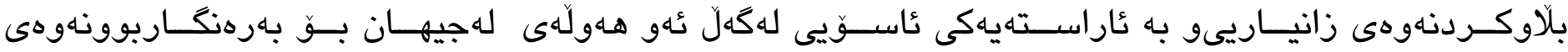

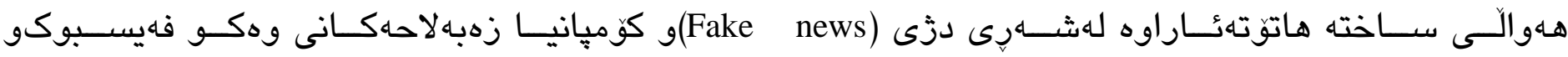

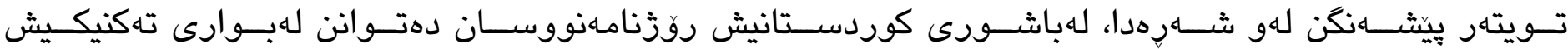
باردنكاريى دياردهى هـاوالى ساخته بينهوه.

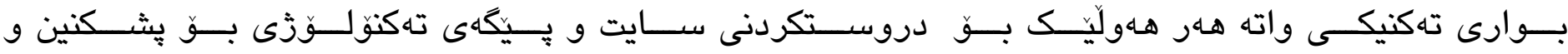

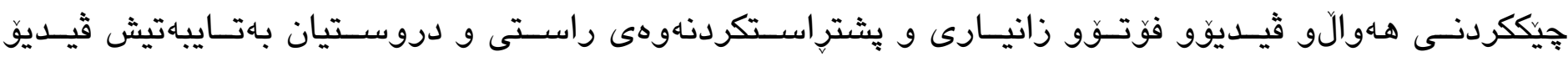

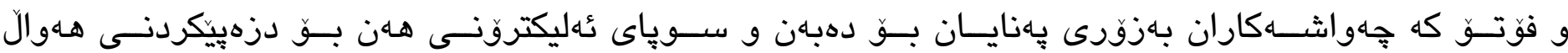

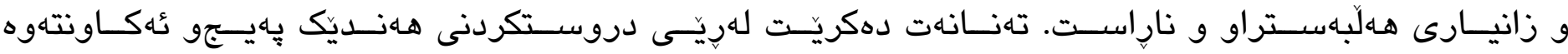

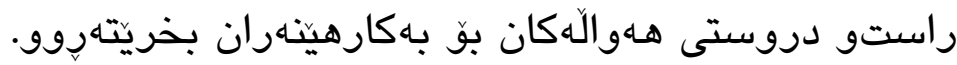

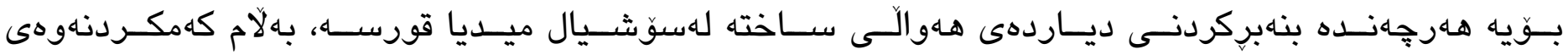

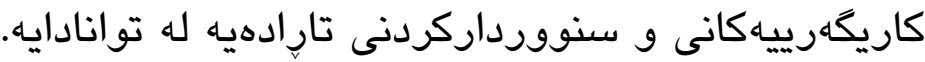

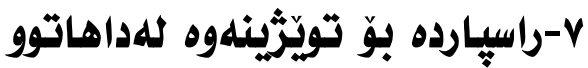

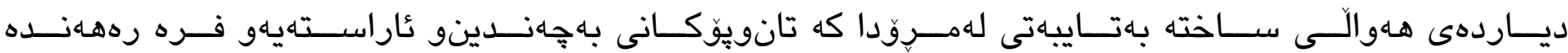

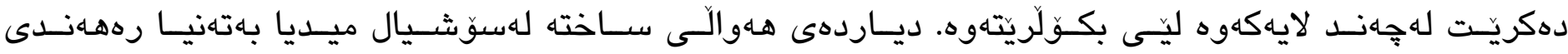

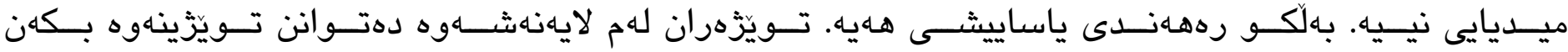

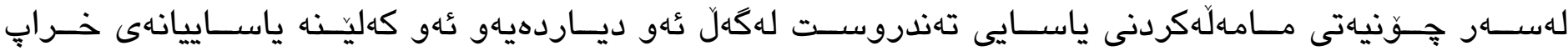

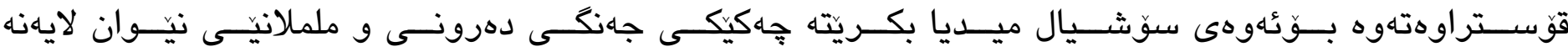

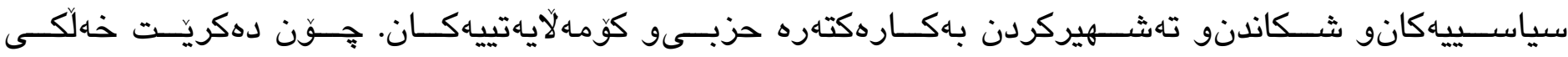

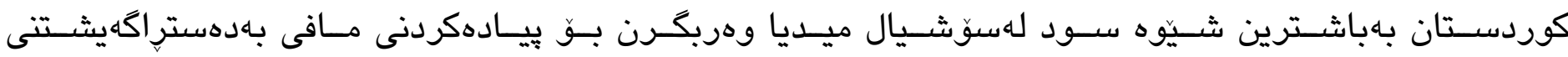

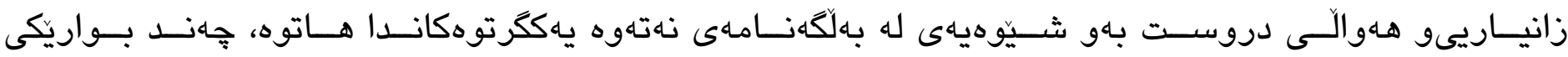

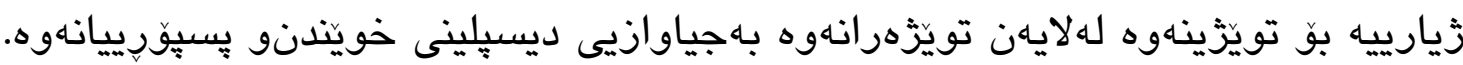

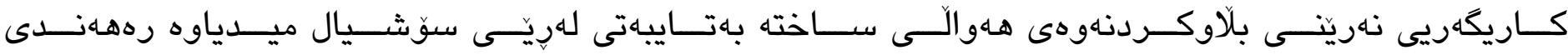

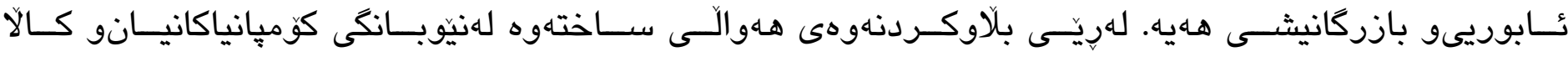

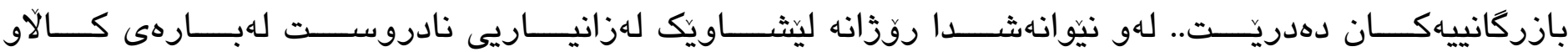

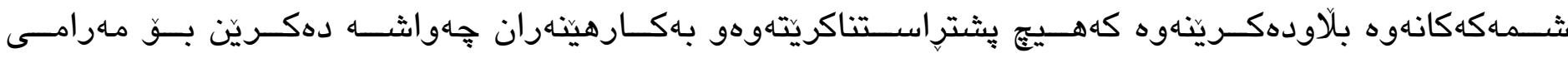

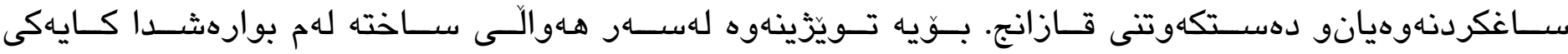

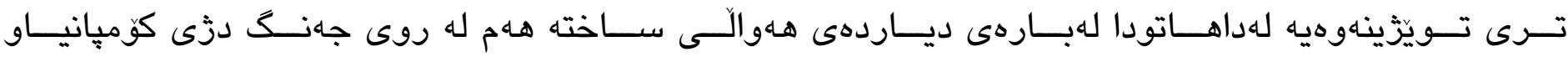

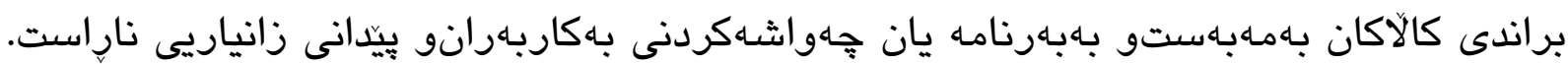




\title{
Fake News in Social Kurdish Media in Kurdistan Region
}

\section{Nawzad Sadiq Muhammad}

Media Technical Department, Technical College of Administration, Sulaimani Polytechnial University, Sulaimani, Kurdistan Region, Iraq.

E-mail: nozadsm@spu.edu.iq

\section{Kamil Omer Sleman}

Media Department, Humanities college, University of Sulaimani, Sulaimani, Kurdistan Region, Iraq.

E-mail: Kamil.sleman@univsul.edu.iq

\begin{abstract}
:
Fake news becomes a phenomenon in the Kurdish social media. The easiness of use and the political and social environmental crisis of northern Kurdistan besides non-professional dealing by a number of journalists worsen the situation. Despite the fact that fake news does not stemmed from the modern technology of information and the advent of using media for psychology and propaganda war but, the easiness of accessing social media makes the online platforms to be the main mediums of disseminating fake news.

The openness of northern Kurdistan towards new communication technology and the semi-freedom of journalistic working and partisan activities help this part of the world to be a spot area for spreading fake news phenomenon; which became an interesting topic for many scholars around the world mainly after the presidential elections of United States of America in 2016.

In this exploratory study, focus group interview used for collecting data and thematic analysis approach adopted for analysing it. Results show that spreading fake news through the Kurdish social media becomes a prevailing phenomenon. Various political and economy purposes can be identified behind disseminating fake news. Adding to increasing activity of variety of pages and accounts created with this respect through different names.

Although of prevailing of the phenomena, a number of procedures can be taken in order to put a line for common of the phenomena including covering fake news through creating parasite account and pages and detecting the source of such piece of information.
\end{abstract}

Keywords: Fake News, Social Media, Political Crisis, Kurdistan Region, Mis-information, Confrontation. 
Abbasi, Ahmed, Zhu Zhang, David Zimbra, Hsinchun Chen, and Jay F. Nunamaker Jr. 2010. "Detecting Fake Websites: The Contribution of Statistical Learning Theory.” MIS Quarterly 34 (3): 435-461.

Allcott, H., \& Gentzkow, M. (2017). Social media and fake news in the 2016 election. Journal of Economic Perspectives, 2(31), 211e236. https://doi.org/10.1257/ jep.31.2.211

Allcott, Hunt, and Matthew Gentzkow. 2017. "Social Media and Fake News in The 2016 Election." Journal of Economic Perspectives 31 (2): 211-236. doi:10.1257/jep.31.2.211.

Watson, A. (2020). Fake news worldwide - Statistics \& Facts, available from: http:// www.statista.com/topics/6341/fake-news-worldwide/\#dossierSummary (Accessed 20th May 2021).

Bernhard, U., \& Dohle, M. (2015). Corrective or confirmative actions? Political online participation as a consequence of presumed media influences in election campaigns. Journal of Information Technology \& Politics, 12(3), 285e302. https:// doi.org/10.1080/19331681.2015.1048918.

Bradshaw, S., \& Howard, P. N. (2018). Challenging truth and trust: A global inventory of organized social media manipulation. The Computational Propaganda Project.

Cantril, Hadley. 2005. The Invasion from Mars. Princeton, NJ: Princeton University Press.

Colliander, J. (2019). "This is fake news": Investigating the role of conformity to other users' views when commenting on and spreading disinformation in social media. Computers in Human Behavior, 97, $202-215$. Guess, A., Nagler, J., \& Tucker, J. (2019). Less than you think: Prevalence and predictors of fake news dissemination on Føءءsacebook. Science Advances, 5(1), eaau4586.

Jang, S. M., \& Kim, J. K. (2018). Third-person effects of fake news: Fake news regulation and media literacy interventions. Computers in Human Behavior, 80, 295e302.

Ma, J., Gao, W., Mitra, P., Kwon, S., Jansen, B. J., Wong, K. F., et al. (2016). Detecting rumors from microblogs with recurrent neural networks (pp. 3818e3824). In IJCAI.

Marcus, Joyce. 1993. Mesoamerican Writing Systems: Propaganda, Myth, and History in Four Ancient Civilizations. Princeton, NJ: Princeton University Press

Mattiuzzi, C., \& Lippi, G. (2020). Which lessons shall we learn from the 2019 novel coronavirus outbreak? Annals of Translational Medicine, 8(3), 48.

Mele, N., Lazer, D., Baum, M., Grinberg, N., Friedland, L., Joseph, K., et al. (2017). Combating fake news: An agenda for research and action. https:// shorensteincenter.org/wp-content/uploads/2017/05/CombatingFakeNewsAgenda-for-Research-1.pdf. 
Mihailidis, P., \& Viotty, S. (2017). Spreadable spectacle in digital culture: Civic expression, fake news, and the role of media literacies in "post-fact" society. American Behavioral Scientist, 4(61), 441e454.

https://doi.org/o0r.g1/107.171/ 0770/0200726746241271770011217.

Pennycook, G., Cannon, T. D., \& Rand, D. G. (2017). Implausibility and illusory truth: Prior exposure increases perceived accuracy of fake news but has no effect on entirely implausible statements. Available at: SSRN https://ssrn.com/ abstract1/42958246.

S. Mo Jang, Tieming Geng b , Jo-Yun Queenie Li a , Ruofan Xia b , Chin-Tser Huang, Hwalbin Kim, Jijun Tang. (2018). "A computational approach for examining the roots and spreading patterns of fake news":

Evolution tree analysis. Computers in Human Behavior, 84 (2018) 103-113.available on: https://doi.org/10.1016/j.chb.2018.02.032

Richard Swedberg. 2018. Does Speculation Belong in Social Science Research?, Sociological Methods \& Research, 47,3:1-30.

Thorson, Emily. 2008. "Changing Patterns of News Consumption and Participation.” Information, Communication and Society 11 (4): 473-489. doi:10.1080/13691180801999027.

Verizon.2021. A Guide to Misinformation: How to Spot and Combat Fake News, available from: http:// www.verizon.cominfo/technology/fake-news-on-social-media (Accessed 20th May 2021).

Wardle, Claire. 2017. “Fake News.” It’s Complicated. https://medium.com/1st-draft/fake-newsits-complicatedd0f773766c79. 